\author{
UNIVERSIDADE DE SÃO PAULO - USP \\ FACULDADE DE ECONOMIA, ADMINISTRAÇÃO E CONTABILIDADE \\ DEPARTAMENTO DE ECONOMIA \\ PROGRAMA DE PÓS-GRADUAÇÃO EM ECONOMIA
}

\title{
Impacto do viés judicial sobre o mercado de crédito: Evidências para São Paulo
}

\author{
Pedro Henrique Duca Amoni
}

Orientador: Gabriel de Abreu Madeira

São Paulo, Brasil

2020 
Prof. Dr. Vahan Agopyan

Reitor da Universidade de São Paulo

Prof. Dr. Fábio Frezatti

Diretor da Faculdade de Economia, Administração e Contabilidade

Prof. Dr. José Carlos de Souza Santos

Chefe do Departamento de Economia

Prof. Dr. Ariaster Baumgratz Chimeli

Coordenador do Programa de Pós-Graduação em Economia 
PEDRO HENRIQUE DUCA AMONI

\section{Impacto do viés judicial sobre o mercado de crédito: Evidências para São Paulo}

Dissertação apresentada ao Departamento de Economia da Faculdade de Economia, Administração e Contabilidade da Universidade de São Paulo como requisito parcial para a obtenção do título de Mestre em Ciências.

Orientador: Gabriel de Abreu Madeira

Versão Original

São Paulo, Brasil 


\section{Amoni, Pedro}

Impacto do viés judicial sobre o mercado de crédito: Evidências para São Paulo / Pedro Amoni. - São Paulo, . $55 \mathrm{p}$.

Dissertação (Mestrado) - Universidade de São Paulo, . Orientador: Gabriel de Abreu Madeira.

1. Viés Judicial. 2. Mercado de Crédito. 3. Fricções Financeiras. I. Universidade de São Paulo. Faculdade de Economia, Administração e Contabilidade. II. Título. 
Pedro Henrique Duca Amoni

\section{Impacto do viés judicial sobre o mercado de crédito: Evidências para São Paulo}

Dissertação apresentada ao Departamento de Economia da Faculdade de Economia, Administração e Contabilidade da Universidade de São Paulo como requisito parcial para a obtenção do título de Mestre em Ciências.

Gabriel de Abreu Madeira

Orientador

Rafael de Vasconcelos Xavier Ferreira

Sergio Naruhiko Sakurai

Luciana Yeung

São Paulo, Brasil

2020 



\section{Agradecimentos}

Antes de tudo, agradeço aos meus pais, Tereza e Fernando, por me apoiarem em minhas jornadas. Se acumulo algumas poucas realizações na vida, vocês são os principais responsáveis. Juntamente aos dois, agradeço ao meu irmão, Thiago, que sempre me apoiou e torceu pelo meu sucesso.

À Júlia, agradeço não apenas pelo companheirismo nesses poucos mais de dois anos de mestrado, mas por ter sido essencial em todo o período que estamos juntos. Te amo! Sem você para compartilhar meus medos e aflições ao decidir encarar meu sonho de estudar economia eu não estaria aqui. Minha gratidão será eterna.

Aos meus amigos de Belo Horizonte, dirijo um especial agradecimento pela preocupação e o companheirismo de cada um. Vocês foram essenciais para aliviar o estresse desse período nos momentos em que estive em casa. Assumindo o risco do esquecimento, gostaria de citar nominalmente alguns que contribuíram com esse trabalho: Rafael Felizardo, Carlos Benjamim, Rodrigo Vieira, obrigado por ajudarem a resolver minhas dúvidas quanto ao universo jurídico; Stefano Ferrara, nossas conversas a respeito do mercado de crédito e processos de execução de dívidas foram fundamentais para mim; Matheus Sampaio, seu auxílio para montar a base de dados fez deste um trabalho melhor. Obrigado a todos!

Ao recentes amigos que fiz na FEA, obrigado por fazerem desses anos um período muito mais prazeroso. Compartilhar as dificuldades dessa jornada com pessoas como vocês é um privilégio. Espero que continuemos em contato mesmo seguindo caminhos distintos. E, claro, não posso perder a chance de me desculpar por amola-los tanto com meus problemas da dissertação. Este texto é uma obra conjunta com vocês.

Dando sequência aos responsáveis por este trabalho, gostaria de agradecer à figura central deste texto e meu orientador, Gabriel Madeira. Este trabalho somente foi possível pela sua disponibilidade, dedicação e interesse. Seus conselhos, direcionamentos e capacidade em guiar para os caminhos corretos, mas sempre dando liberdade às minhas ideias, fez tudo parecer mais fácil.

Também não posso deixar de agradecer aos professores Rafael Ferreira e Raphael Corbi pelos conselhos e ponderações importantes ao trabalho. Foi um prazer poder contar com o apoio de pesquisadores talentosos como vocês.

Por fim, gostaria de agradecer à USP, ao departamento de economia, a todas as pessoas envolvidas no funcionamento da universidade e ao $\mathrm{CNPq}$ pelo apoio financeiro durante todo o período. 

"E os pactos sem a espada não passam de palavras sem força para dar qualquer segurança a ninguém. Portanto, apesar das leis de natureza (que cada um respeita quando tem vontade de respeitá-las e quando pode fazê-lo com segurança), se não for instituído um poder suficientemente grande para nossa segurança, cada um confiará, e poderá legitimamente confiar, apenas em sua própria força e capacidade, como proteção contra todos os outros." 



\section{Resumo}

Exploramos a distribuição aleatória de processos entre juízes para avaliar como os bancos reagem ao depararem com magistrados mais ou menos favoráveis a eles. Partimos das informações do saldo de crédito dos quatro grandes bancos comerciais do Brasil e cruzamos com informações de sentenças emitidas pela Justiça Comum do Estado de São Paulo em que esses bancos foram réus na ação. Construímos uma variável instrumental a partir das decisões judiciais que considera todas as instituições financeiras - não apenas as que observamos na amostra final - para medir o nível de leniência de cada juiz em relação aos demais magistrados de sua jurisdição. Encontramos evidências que suportam a ideia de que instituições financeiras reagem restringindo crédito quando observam um judiciário desfavorável às mesmas.

Palavras-chaves: Viés Judicial, Fricções Financeiras, Mercado de Crédito. 



\section{Abstract}

We exploit the random assignment of cases to judges to assess how banks react when facing magistrates who are more or less friendly to them. From the balance information of the four major commercial banks in Brazil we cross-referenced this data to the information of sentences issued by the State Justice of São Paulo whose these banks are defendants in the lawsuit. We constructed an instrumental variable using judicial decisions that considers all financial institutions - not just those observed in the final sample - to measure the level of leniency of each judge compared to other magistrates in the same jurisdiction. This paper finds evidences that support the idea that financial institutions reacts constraining the credit offer when observed a not favorable justice.

Key-words: Judicial Bias, Financial Frictions, Credit Market. 



\section{Sumário}

INTRODUÇÃO $\ldots \ldots \ldots \ldots \ldots \ldots \ldots \ldots$

2 CONTEXTUALIZANDO A ATUAÇÃO DO JUDICIÁRIO . . . . . 25

3

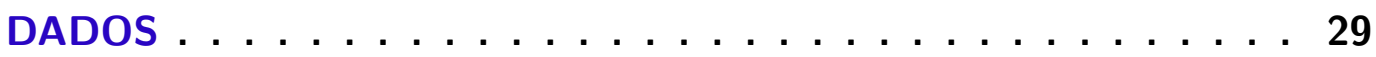

4 ESTIMANDO O IMPACTO DAS DECISÕES JUDICIAIS SOBRE

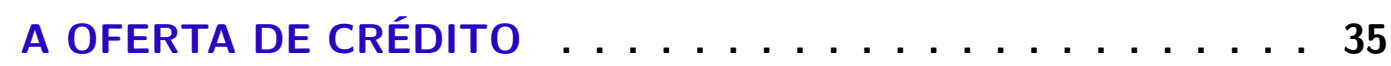

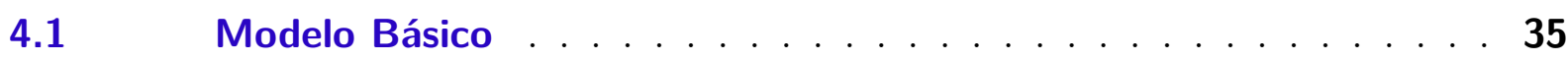

$4.2 \quad$ Abordagem por Variável Instrumental . . . . . . . . . . . 36

$4.3 \quad$ Validade do Instrumento e LATE . . . . . . . . . . . . . . . 38

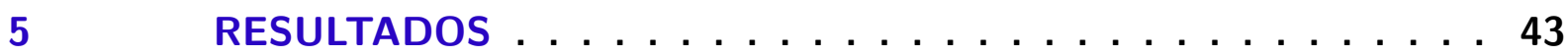

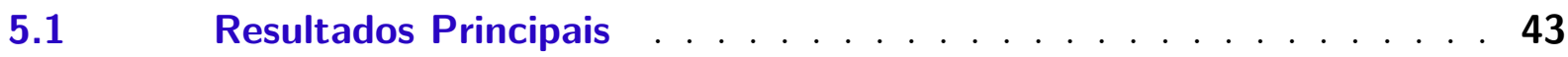

$5.2 \quad$ Outros Resultados e Robustez . . . . . . . . . . . . . . . . 47

$6 \quad$ CONCLUSÃO $\ldots \ldots \ldots \ldots \ldots \ldots \ldots$

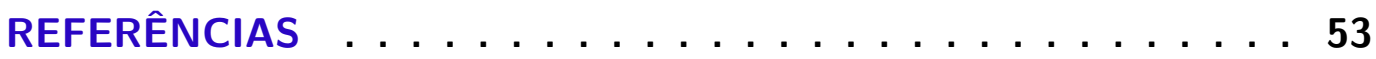





\section{Lista de ilustrações}

Figura 1 - Primeiro Estágio . . . . . . . . . . . . . . . . . . 41

Figura 2 - Variabilidade do Nível de Leniência por Tamanho de Comarca . . . . 50 



\section{Lista de tabelas}

Tabela 1 - Estatística descritiva de decisões judiciais . . . . . . . . . . . 31

Tabela 2 - Estatística descritiva por comarca . . . . . . . . . . . 33

Tabela 3 - Estatísticas descritivas dos dados finais . . . . . . . . . . . . . . 33

Tabela 4 - Teste de aleatorização na distribuição de processos . . . . . . . . . . 39

Tabela 5 - Forma reduzida . . . . . . . . . . . . . . 40

Tabela 6 - Primeiro Estágio . . . . . . . . . . . . . . . . 40

Tabela 7 - Modelo Simples MQO . . . . . . . . . . . . . . . 44

Tabela 8 - Mínimos Quadrados em Dois Estágios . . . . . . . . . . . 45

Tabela 9 - Resultados Eliminando 1\% dos Maiores e Menores Valores de Leniência 47

Tabela 10 - Subamostra Excluindo as Maiores Comarcas . . . . . . . . . . . . . 48

Tabela 11 - Intervalos De Confiança Robustos a Instrumentos Fracos . . . . . . . . 49 



\section{Introdução}

Como discutido por Levine (2005), o desenvolvimento do mercado financeiro é um importante fator para o crescimento de longo prazo de um país. Ao mesmo tempo em que esse é responsável por alocar recursos ao longo do tempo e espaço de forma mais eficiente, existem grandes diferenças em quão bem esse sistema opera. Banerjee e Duflo (2005) apontam como friç̧ões financeiras impedem a alocação de capital em projetos mais produtivos e limitam a adoção de novas tecnologias. Portanto, reduzir restrições ao bom funcionamento do mercado financeiro é um meio importante para a geração de investimentos e desenvolvimento econômico.

De maneira mais geral, para North (1990), a incapacidade de países desenvolverem instituições de baixo custo capazes de forçar o cumprimento de contratos é determinante para o subdesenvolvimento. Djankov et al. (2008) e Porta et al. (1997) mostram que a baixa proteção do direito dos credores pelas instituições de justiça é geradora de imperfeições de mercado e é altamente correlacionada com o desenvolvimento do sistema financeiro. Seguindo essa mesma linha, mas aplicado ao contexto brasileiro, Arida, Bacha e LaraRezende (2005) argumentam que a incerteza jurisdicional é um dos caminhos para se compreender a alta taxa de juros e o subdesenvolvimento do mercado de crédito brasileiro. Os mesmos apontam o viés anti-credor das instituições em geral, dentre estas o poder judiciário, como um dos responsáveis pelos problemas levantados. Entretanto, Yeung (2019) mostra que o Superior Tribunal de Justiça (STJ) não apresenta um comportamento consistente de favorecimento seja ao devedor ou ao credor, mas que existe imprevisibilidade nas decisões. Reforçando a ideia de imprevisibilidade da justiça brasileira, Pinheiro (2003), a partir de questionários aplicados a uma amostra de juízes de primeira e segunda instância em todas as unidades federativas do Brasil, evidencia que a visão dos magistrados quanto à forma de atuação adequada de suas funções varia em larga escala. Referente ao mercado de crédito, as opiniões dos entrevistados divergem ao responder se os contratos devem ser sempre respeitados ou se a busca pela justiça social justifica a violação dos mesmos. Apenas 13,4\% dos entrevistados responderam que a primeira opção deve sempre prevalecer. Verificadas a divergências no posicionamento dos magistrados, temos que o risco atrelado à discricionariedade permitida em um conflito judicial configura um mecanismo de variação no enforcement contratual percebido entre as partes em um processo.

O presente trabalho avalia se instituições financeiras reagem a decisões judiciais desfavoráveis às mesmas, restringindo a oferta de crédito no período seguinte, ao enfrentarem magistrados com maior tendência em favorecer o devedor. O foco do trabalho é o estado de São Paulo por disponibilizar todas as sentenças judiciais de primeira instância 
emitidas desde 2012.

Para isso, partimos de uma base de dados de 351.701 sentenças em que alguma instituição financeira seja ré no processo. Aproveitando da aleatoriedade em que o processo é distribuído entre juízes dentro mesmo foro, avaliamos se os magistrados divergem consistentemente na proporção de decisões a favor de um dos lados em comparação com os demais juízes que fazem parte da mesma jurisdição no mesmo ano. Como medida desta leniência (viés), utilizamos o leave-one-out residual que se baseia em todas as demais observações do mesmo magistrado, menos aquela em questão, da proporção de decisões pró-devedor que ele emitiu. Com esses valores, regredimos contra um conjunto completo de variáveis correspondentes à interação de efeitos fixos de foro e ano, e utilizamos os resíduos estimados como medida de leniência de cada juiz a ser utilizada para aquela observação. Essa abordagem se assemelha à estratégia utlizada em Kling (2006), Chang e Schoar (2013), Dahl, Kostøl e Mogstad (2014), Aizer e Doyle (2015), Dobbie e Song (2015), Dobbie, Goldin e Yang (2018) e Bhuller et al. (2019). Entretanto, como cada instituição financeira observa várias decisões por período, agregamos todos os valores de leniência pela média ponderada da quantidade de sentenças que cada magistrado foi responsável referente à instituição financeira, em uma determinada comarca, em cada trimestre. $\mathrm{O}$ resultado final é que temos o valor da leniência observada pelas instituições financeiras em todo o período como uma composição do nível de leniência de cada juiz que atuou em processos movidos contra a mesma. A partir disso, utilizamos o valor da leniência observada por cada instituição financeira como variável instrumental para a proporção de decisões contrárias às mesmas. Em sequência, cruzamos as informações de decisões judiciais com informações referentes ao saldo de crédito disponível, em cada trimestre e em cada comarca do estado de São Paulo, para cada um dos quatro grandes bancos brasileiros. Utilizamos a proporção de decisões desfavoráveis aos bancos como variável explicativa para a taxa de variação do saldo de crédito no período posterior.

Como principal resultado, encontramos que um aumento de 1 ponto percentual na proporção de decisões pró-devedor em um trimestre, devido ao banco ter enfrentado juízes mais lenientes, reduz em 0,08 pontos percentuais a taxa de crescimento de crédito no período seguinte. Isso é equivalente a um aumento de um desvio padrão na variável explicativa impactar negativamente em 3 pontos percentuais, ou 0,38 desvio padrão, a taxa de variação do saldo de crédito no período posterior. Não encontramos resultados estatisticamente significativos e diferentes de zero para o modelo que não leva em consideração a variável instrumental proposta.

De forma a validar o resultado, em um segundo momento excluímos observações correspondentes a $1 \%$ dos valores superiores e inferiores de leniência. Como são valores extremos com baixa probabilidade de ocorrência, resultados encontrados ainda mais significativos afastam a hipótese de que estávamos sendo direcionados por ruídos no cálculo 
do instrumento. Em sequência discutimos possíveis limitações do desenho de pesquisa ao analisarmos comarcas com alta movimentação judicial e mostramos que, de fato, ao eliminarmos essas regiões, os resultados ficam ainda mais expressivos. Por fim, para afastar qualquer hipótese de viés e problemas de inferência no caso de instrumentos fracos, apresentamos uma comparação do intervalo de confiança de Wald com o de AndersonRubin que é robusto independentemente da força do instrumento no contexto de uma única variável endógena exatamente identificada.

Este trabalho se relaciona com uma extensa literatura que avalia a capacidade das leis e do poder judiciário em garantir os direitos do credor e seus impactos sobre a economia. Os trabalhos de La Porta et al. $(1997,1998)$ iniciam uma grande agenda de pesquisa para elucidar os efeitos que as características de diferentes sistemas jurídicos exercem sobre os mercados financeiros de vários países. Mais especificamente, esses trabalhos focam a atenção para a qualidade de proteção dos direitos dos investidores e credores em diferentes tradições legais. Também explorando dados de diferentes países, Laevena e Majnoni (2005) e Djankov et al. (2008) encontram que sistemas judiciais mais efetivos em garantir os direitos dos credores e investidores estão correlacionados a um maior desenvolvimento do mercado financeiro e menores taxas de juros. Reduzindo a unidade de análise, mas mantendo objetivos similares, Jappelli, Pagano e Bianco (2005) utilizam as variações da qualidade do sistema judiciário entre diversas regiões da Itália para mostrar que quanto maior a eficiência judicial, menores restrições são impostas ao mercado e maior a quantidade de empréstimos realizados. No trabalho de Visaria (2009), ela aproveita a introdução de tribunais de recuperação de crédito em estados da Índia para apresentar evidências de que o aumento na eficiência em casos de recuperação de crédito, gerados por tal reforma da estrutura judicial, reduzem tanto o índice de não pagamento quanto a taxa de juros dos contratos de crédito. No mesmo espírito, Ponticelli e Alencar (2016) exploram a variação da produtividade entre diferentes comarcas no Brasil para mostrar que uma maior ineficiência judicial causa impactos negativos nas diversas variáveis do mercado de crédito e também sobre a economia real. O presente trabalho apresenta novas evidências que corroboram com literatura apresentada, mas em um nível ainda menor de análise. Buscou-se apresentar novos resultados explorando a discricionariedade que cada juiz exerce sobre o processo legal. Com isso, pôde-se estimar qual o impacto que diferentes juízes exercem sobre o mercado de crédito ao estabelecerem diferentes níveis de proteção dos direitos do credor e qualidade de enforcement contratual. Nesse ponto, assemelha-se ao trabalho de Chang e Schoar (2013) que mostra que empresas não liquidadas, por terem sido julgadas por juízes com propensão em favorece-las em processos de falência, apresentam pior desempenho que as demais. Apesar próximos na metodologia, o objetivo deste trabalho é distinto, já que concentramos nossos esforços em determinar o impacto que decisões proferidas por juízes com diferentes níveis de vieses exercem sobre o mercado de crédito. 
Levando em conta o grande esforço para ampliação e melhoria do mercado de crédito brasileiro, esse trabalho se junta a outras relevantes contribuições que documentam os efeitos das alterações regulatórias e atuação judicial sobre esse mercado. A partir de uma decisão judicial contrária à possibilidade de dedução do débito em folha de pagamento do tomador de crédito consignado, Costa e Mello (2006) apresentam evidências de que o risco jurídico gerado por decisões controversas da justiça brasileira é um limitador da expansão de crédito. Observando exatamente o mesmo instrumento de crédito, Coelho, Mello e Funchal (2012) mostram a expansão do crédito pessoal e diminuição das taxas de juros gerados pela ampliação da abrangência do crédito consignado para os trabalhadores do setor privado. Fica claro que mudanças legais e o comportamento do judiciário na aplicação da lei são indissociáveis para o entendimento de como o ambiente regulatório impacta a economia. Novamente, temos o caso em que Araujo, Ferreira e Funchal (2012) apresentam os efeitos positivos da nova lei de falências introduzida no Brasil, com um expressivo aumento no crédito de longo-prazo e menores taxas de juros, e Ponticelli e Alencar (2016) mostram evidências de que os benefícios dessa inovação legal depende da eficiência da aplicação da lei. Esse último aproveita a heterogeneidade da eficiência judicial entre regiões do país para mostrar que tal inovação legal, que busca aumentar a proteção dos direitos do credor, apenas geram resultados positivos se o judiciário corresponde aplicando a lei com eficiência e agilidade. No caso do presente trabalho, contribuímos para essa discussão apontando que além das decisões de grande repercussão, melhorias regulatórias no mercado, ou eficiência judicial, também é importante olharmos para como as decisões de conflitos jurídicos são tomadas. A possibilidade do magistrado, mesmo que em primeira instância, exercer um poder discricionário na resolução de conflitos impactando economicamente a sociedade, abre uma discussão se a busca por maior rapidez na resolução de conflitos e inovações legais são suficientes para melhorar a segurança jurídica.

Por fim, este trabalho se relaciona à literatura teórica de contratos que introduzem o enforcement judicial na decisão dos agentes em realizar transações. Podemos novamente citar Jappelli, Pagano e Bianco (2005) que apresentam um modelo no qual a qualidade do judiciário influencia a quantidade de crédito consumido e a taxa de juros cobrada. Em Gennaioli (2013), o autor explicita que, na existência de viés judicial, contratos não contingentes serão preferíveis de modo a proteger o lado mais frágil. Já Madeira (2014) mostra que a imperfeição do judiciário em liquidar projetos em caso de descumprimento do contrato pelo devedor gera restrição de crédito e também impacta o tamanho do dos projetos financiados. Na sequência do trabalho apresentamos evidências que vão de encontro aos argumentos de que o comportamento judicial é uma peça relevante na compreensão do funcionamento do mercado de crédito. 


\section{Contextualizando a Atuação do Judiciário}

Este capitulo tem como objetivo contextualizar o ambiente institucional vigente em conflitos judiciais provenientes da relação credor-devedor no Brasil. Definiremos alguns termos que serão explorados ao longo do trabalho e, resumidamente, apresentaremos o arcabouço legal e a estrutura organizacional que moldam o conflito judicial de ações originárias da contestação de contratos de crédito.

O primeiro ponto a ser esclarecido é que o Código de Defesa do Consumidor (CDC) estabelece que o contrato de crédito é uma relação de consumo. O Superior Tribunal de Justiça (STJ) também já se manifestou de forma a confirmar essa posição (WAMBIER, 1996; PASQUALOTTO, 2002). Estando esses contratos submetido ao CDC, a competência do julgamento de causas relativas a esse tipo de relação comercial é, como regra geral, o foro de domicílio do devedor. Ainda, como forma de proteger o consumidor, se for desejo do mesmo nas ações que atua como parte ativa, o foro competente poderá ser o de domicílio do réu. Apesar dessa flexibilização, o próprio STJ já se manifestou por não ser possível a escolha sem critérios de onde ajuizar a ação ${ }^{1}$.

Conclui-se que há limitações na possibilidade de comportamento estratégico em que o devedor escolha o local em que irá propor a ação contra o credor e vice-versa. Também, devido ao menor custo de transação, podemos imaginar que o domicílio tanto do devedor quanto o do credor, sendo este um banco com atuação local, será o mesmo. Entretanto, cabem algumas explicações para que possamos compreender o que representa o foro de competência e outros aspectos relevantes da justiça explorados pelo trabalho.

Iniciando pela estrutura judicial, esse poder é regulado pelos artigos 92 a 126 da Constituição Federal de 1988 (CF/88). O primeiro desses artigos estabelece que os órgãos de sua composição são o Supremo Tribunal Federal (STF), Tribunais Superiores Federais, Regionais e Estaduais, tanto da Justiça Comum como da Justiça Especializada.

Dessa forma, o poder judiciário é composto por Justiça Especial (Eleitoral, Trabalhista e Militar) e Justiça Comum. Nessa última, há a separação entre Justiça Estadual e Justiça Federal. Como não é de interesse detalhar quais as competências estritas de cada uma das Justiças estabelecidas pela CF/88, resta-nos saber que contratos de crédito tem como competência a Justiça Estadual, salvo quando envolva a União, autarquias e

1 Superior Tribunal de Justiça STJ - EMBARGOS DE DECLARAÇÃO NO AGRAVO REGIMENTAL NOS EMBARGOS DE DECLARAÇÃO NO CONFLITO DE COMPETÊNCIA : EDcl no AgRg nos EDcl no CC 116009 PB 2011/0035408-1. Disponível em: https://stj.jusbrasil.com.br/jurisprudencia/21598409/embargos-de-declaracao-no-agravo-regimentalnos-embargos-de-declaracao-no-conflito-de-competencia-edcl-no-agrg-nos-edcl-no-cc-116009-pb-20110035408-1-stj/inteiro-teor-21598410?ref=serp 
empresas públicas (VELLOSO, 1995). Ou seja, todos os bancos Brasileiros privados estão sujeitos à Justiça Estadual enquanto bancos com o capital completamente pertencentes à União, à Justiça Federal. Empresas de capital misto tem como competência a Justiça Comum Estadual como manifestado na súmula 556 do STF,

Ainda definido constitucionalmente, a Justiça Comum Estadual se divide em primeira instância, composta por juízes responsáveis pelo julgamento dos processos, e segunda instância, que são os Tribunais de Justiça Estaduais - órgãos colegiados responsáveis por julgar os recursos das sentenças do juiz singular. Acima dos Tribunais Estaduais há o STJ e, sobre todos os demais, o STF. Esses últimos também são órgãos colegiados e são responsáveis por resguardar normas infraconstitucionais e constitucionais, respectivamente.

Ou seja, uma ação proveniente de um conflito relativo a um contrato de crédito, com exceção dos bancos com capital integral da União, tem origem na primeira instância da Justiça Comum Estadual. Para compreendermos como será a definição do juiz responsável pelo caso, cabe elucidarmos o que são comarcas, foros e varas. Seguiremos as explicações de Gonçalves (2017) e o decreto-lei 158 de 1969 no qual o então governador de São Paulo dispõe sobre a organização judiciária do Estado.

Por comarca, compreendemos como unidade territorial em que o juiz de primeira instância exerce sua jurisdição. Corresponde territorialmente aos limites de uma ou mais cidades a depender da demanda judicial em cada região. Cada comarca constitui um foro e esses se confundem geograficamente e em definição. Porém, a Lei de Organização Judiciária do Estado de São Paulo abre uma exceção ao considerar o foro como uma unidade jurídico-administrativa dentro da comarca. Ou seja, uma comarca pode conter vários foros, como ocorre unicamente na comarca da capital do Estado que é composta por um foro central e 14 foros regionais. Cada foro é composto por uma ou mais varas. Essas são divisões de jurisdições em função da matéria da ação e são comandadas por um juiz titular. Essas varas podem ou não serem especializadas em um tipo de matéria, por exemplo, processos penais, direito de família ou então apreciar apenas processos de falência.

Dessa forma, o juiz responsável pelo tipo de processo em questão será aquele que atua no foro competente à ação e lotado em varas responsáveis por apreciar a matéria em questão. Havendo mais de uma vara possível, os processos são distribuídos por sorteio entre elas. Tanto as regras de definição de competência de foro como a aleatorização da distribuição dos processos entre as varas visam manter o preceito constitucional do juiz natural que prevê a independência e imparcialidade do julgador. Da mesma forma que o STJ já decidiu por garantir o respeito do foro competente - como mostramos no início dessa seção -, o não cumprimento da distribuição aleatória já foi motivo de liminar emitida pelo mesmo tribunal anulando o processo $^{2}$.

2 Superior Tribunal de Justiça STJ - HABEAS CORPUS: HC 12403 SE 2000/0019528-6 
Fica claro que não há possibilidade de escolha do juiz que será responsável pelo julgamento do caso. A limitação de onde a ação poderá ser ajuizada define a composição de magistrados possíveis, enquanto a aleatoriedade da distribuição dos processos entre varas garante que não será permitida a escolha de quem será o responsável pela ação.

Uma última forma de variação entre os juízes responsáveis pelos processos dentro de um mesmo foro é a alteração da composição dos magistrados ao longo do tempo. A Lei Orgânica da Magistratura do Estado de São Paulo estabelece critérios para remoção e promoção de magistrados, sendo que esses começam em comarcas iniciais menores e são promovidos até comarcas maiores ou mesmo para a segunda instância. Além disso, por preferências locacionais, caso for o desejo do magistrado, ele pode pleitear a mudança para comarcas de mesmo nível. Além das movimentações de juízes entre comarcas, existem períodos de férias e afastamento em que juízes substitutos ou aqueles lotados em outras varas cobrem a função do juiz titular. Esses dois mecanismos de variação na composição dos magistrados da comarca introduz mais um componente de variação sobre a definição do magistrado responsável por um determinado processo.

Diante o exposto, fica claro que a escolha do juiz responsável por qualquer processo é restringida por normas que definem a distribuição aleatória entre juízes condicional ao foro em que a ação foi ajuizada. Quanto à jurisdição responsável pela resolução do conflito, essa também é restrita a previsões legais e limitam o comportamento estratégico do polo ativo da ação quanto à escolha do foro competente. No restante do trabalho iremos explorar tais características do poder judiciário brasileiro em nossas análises.

disponível em: https://stj.jusbrasil.com.br/jurisprudencia/7940084/habeas-corpus-hc-12403-se-20000019528-6-stj?ref=serp2O 



\section{Dados}

As análises desenvolvidas no presente trabalho utilizaram-se de informações a respeito das decisões judiciais em primeira instância da justiça estadual de São Paulo e do balancete mensal por município e agencia informado pelos bancos múltiplos com carteira comercial, atuantes no estado de São Paulo, ao Banco Central do Brasil (BACEN). Ambas informações estão disponíveis publicamente através do banco de sentenças do Tribunal de Justiça de São Paulo (TJSP) ${ }^{1}$ e pelo relatório de Estatística Bancária Mensal por Município (ESTBAN) ${ }^{2}$.

A partir das sentenças de primeira instância disponibilizadas pelo TJSP, montou-se um banco de dados que reúne informações a respeito de decisões judiciais de processos cíveis da justiça de primeiro grau do estado de São Paulo, com sentença proferida, em que a parte requerida foram empresas ofertantes de crédito. A utilização apenas de sentenças em que as instituições financeiras sejam ré se deve ao fato de consistirem nos casos em que o devedor busca de alguma forma o rompimento do contrato acordado. Essas são situações mais propícias de manifestação da discricionariedade do juiz do que ações de cobrança e execução de dívidas quais a comprovação do não pagamento não deixa grandes dúvidas e margem à atuação judicial. Além disso, como uma grande uma grande parte dos instrumentos de crédito estão sujeitos à execução de dívidas de forma extrajudicial, a judicialização desses contratos ocorrem via contestação do devedor. Outro fato que justifica a exclusão de processos em que o credor atua como parte ativa, é que a sentença ocorre apenas após a quitação da dívida. O resultado disso é que vários processos se alongam muito tempo ou então não são concluídos, sendo impossível observarmos seu resultado no banco de sentenças. Expostos os fatos, esse trabalho considera que as decisões movidas contra instituições financeiras, se não completamente suficientes para explicar o impacto das decisões judiciais sobre o mercado de crédito, são ao menos uma forte aproximação do comportamento judicial na relação credor-devedor.

As decisões judiciais são disponibilizadas por um mecanismo de busca em que filtramos processos do tipo "procedimento comum cível" ${ }^{3}$ entre os dias 01 de março de 2011 a 31 dezembro de 2018. Como as sentenças são disponibilizadas em texto, no próprio site, extraiu-se as informações não estruturadas de julgados de primeiro grau utilizando-se da técnica de raspagem de dados (web scraping) para obter o número, classe, assunto, magistrado, comarca, foro, vara, data e a ementa da sentença de cada processo julgado. Foram excluídas sentenças de varas especializadas, resultando em 2.633.136 decisões

1 Disponível em https://esaj.tjsp.jus.br/cjpg/

2 Disponível em https://www4.bcb.gov.br/fis/cosif/estban.asp?frame=1

3 Classe de processo padrão utilizada em disputas contratuais típicas da relação credor-devedor. 
judiciais.

Destas sentenças foram extraídos do textos das ementas os nomes do requerente e requerido em cada processo. Foram utilizados de padrões de escrita que identificam as partes do processo para capturar os nomes dos envolvidos.

De posse das decisões judicias com as informações necessárias extraídas, novamente nos aproveitamos do padrão de palavras que expressam a decisão do juiz para definir a parte vencedora do processo. As sentenças foram classificadas entre homologadas (quando há acordo ou se acata o questionamento judicial pela parte requerida), procedente (a favor do requerente), improcedente (a favor do requerido) e parcialmente procedente (quando o juiz acata parte dos pedidos propostos na ação). No presente trabalho, consideramos decisões parcialmente procedentes e procedentes conjuntamente, uma vez que foram sentenças a favor do devedor em pelo menos algum ponto. Ao final desta etapa, restaram 2.389.199 sentenças (91\% do total) em que foram classificadas e extraídas os nomes das partes do processo.

Como validação, verificou-se 238 sentenças escolhidas aleatoriamente para análise da acurácia dos dois procedimentos anteriores. Dentre as sentenças verificadas, todas continham as partes corretamente extraídas e apenas 9 (3,7\%) continham erros de classificação. Tal resultado nos garante que, dentre as sentenças classificadas, $93 \%$ a $99 \%$ estão corretas a um nível de significância de 5\%.

O passo seguinte consistiu em separar, dentre os processos classificados, aqueles em que a parte passiva (requerido) foram instituições financeiras ofertantes de crédito. A partir de informações do BACEN disponíveis em seu site ${ }^{4}$, foram listadas todas as instituições financeiras em funcionamento no Brasil desde 2010. O mesmo foi feito a partir das informações do relatório mensal do ESTBAN. De posse dessas informações, devido ao nomes das instituições financeiras serem redigidos nas sentenças de formas diferentes, com erros de grafia ou omissão parcial do nome, realizou-se um fuzz matching ${ }^{5}$ entre os nomes das instituições e a parte requerida de cada processo. Este procedimento foi realizado individualmente para cada lista e posteriormente descartado os processos duplicados.

Foram mantidas apenas as primeiras decisões em cada processo e, para cada um dos grandes bancos (Banco do Brasil, Itaú, Santander e Bradesco), identificou-se seus respectivos processos e de suas subsidiarias. Empresas financeiras que não pertencem a nenhum destes grupos foram mantidas na base, mas não estão individualmente identificadas. Foram eliminadas da base decisões anteriores a 2012, uma vez que, em consulta ao TJSP, foi informado que antes desta data o banco de sentenças não disponibiliza a integralidade das decisões proferidas. Como apresentado na tabela 1 , depois de todos os procedimentos descritos, resultaram em 351.701 sentenças entre 01 de janeiro de 2012 e 31 de dezembro

4 Disponível em https://www.bcb.gov.br/estabilidadefinanceira/relacao_instituicoes_funcionamento

5 Técnica em que se verifica a correspondência aproximada de informações textuais. 
de 2018 com a proporção de decisões pró-devedor sendo em média $42 \%$ do total.

Tabela 1 - Estatística descritiva de decisões judiciais

\begin{tabular}{lcc}
\hline \hline Instituição Financeira & Senteça & Média \\
\hline \multirow{3}{*}{ Todas } & Sem vencedor & 0.22 \\
$\mathrm{~N}=351.701$ & Pró-credor & 0.36 \\
& Pró-devedor & 0.42 \\
& & \\
Banco do Brasil & Sem vencedor & 0.20 \\
$\mathrm{~N}=39.386$ & Pró-credor & 0.24 \\
& Pró-devedor & 0.57 \\
& & \\
Santander & Sem vencedor & 0.27 \\
$\mathrm{~N}=55.078$ & Pró-credor & 0.31 \\
& Pró-devedor & 0.42 \\
Itaú Unibanco & Sem vencedor & 0.28 \\
$\mathrm{~N}=80,496$ & Pró-credor & 0.38 \\
& Pró-devedor & 0.34 \\
& & \\
Bradesco & Sem vencedor & 0.18 \\
$\mathrm{~N}=57,384$ & Pró-credor & 0.35 \\
& Pró-devedor & 0.47 \\
Outros & & \\
$\mathrm{N}=119,357$ & Sem vencedor & 0.20 \\
\hline \hline & Pró-credor & 0.41 \\
& Pró-devedor & 0.40 \\
\hline
\end{tabular}

Existem diferenças entre a proporção de vitórias por cada banco, sendo que o Banco do Brasil sofreu derrotas em 57\% dos casos e o Itaú Unibanco apenas em 34\%. Também há grande variação na quantidade de processos entre bancos e, novamente, os mesmos aparecem nos valores extremos - dessa vez o Banco de Brasil no limite inferior. Os quatro bancos analisados, contando suas subsidiarias, correspondem a quase dois terços do total de processos que compõem a base.

As informações a respeito do saldo de crédito presente no balanço de cada banco foram extraídas do relatório mensal por município e agência fornecidos através do ESTBAN com informações consolidadas dos balancetes enviadas pela própria instituição financeira ao BACEN. Os valores de saldo de crédito por banco em cada cidade é obtido pela soma dos saldos da conta VERBETE_140_OPERAÇÕES_CRÉDITO do balancete de cada agência, do mesmo banco, presentes no mesmo município. A agregação por comarca foi realizada utilizando a relação de municípios pertencentes a cada comarca disponibilizados 
pelo Ministério Público de São Paulo (MPSP) ${ }^{6}$ e utilizamos o saldo médio por trimestre para chegar ao valor do montante de crédito disponibilizado em cada período e em cada comarca do Estado de São Paulo. No trabalho foram considerados apenas os quatro maiores bancos comerciais do Brasi ${ }^{7}$ por serem os únicos a possuírem agências em uma grande extensão do território do Estado.

Por fim, para os análises desenvolvidas no decorrer do trabalho, o banco de dados de sentenças judiciais e de saldo de crédito foram agregados em nível de comarca, trimestre e instituição financeira e unificado em uma nova base de dados. Para este trabalho restringimos apenas comarcas que registravam, em todos os períodos, a presença dos quatro bancos observados neste estudo. Com isso, evitamos observar efeitos de entrada e saída de bancos e uniformizamos a amostra para um nível similar de competição bancária e características econômicas que determinam a presença ou não destas instituições financeiras na região. ${ }^{8}$ Das 319 comarcas presentes no estado de São Paulo, restam em nossa base de dados 183 que apresentam em todos os períodos os quatro bancos estudados. As estatísticas descritivas com características do judiciário local e variação de crédito para as comarcas incluídas e excluídas na base de dados estão apresentadas separadamente na tabela 2 . As variáveis apresentadas correspondem aos valores médios por comarca das observações trimestrais. A variação de crédito considera apenas os quatro bancos que são objetos do estudo enquanto as demais variáveis consideram as demais instituições financeiras excluídas da base final.

Observamos que há uma grande diferença entre os dois grupos de comarcas. O total de sentenças por trimestre e concentração de decisões em um único juiz correspondem aos valores mais discrepantes. Nas comarcas excluídas, as poucas sentenças emitidas são concentradas em poucos juízes como reflexo de uma quantidade pequena de varas por comarca. Nesses casos, cada instituição financeira, dentro de cada comarca e em cada período, tendem a ter suas sentenças proferidas pelo mesmo juiz de forma que há uma menor variação do viés judicial observado por diferentes bancos. Além disso, temos que o nível máximo na variação de crédito é maior dentre as comarcas excluídas na amostra. Isso ocorre devido à entrada de novos bancos na região, de modo que incluir essas observações na amostra geraria viés.

Finalmente, a tabela 3 apresenta as estatísticas descritivas da base de dados final com todas as variáveis que utilizaremos nas análises futuras. As observações são referentes a 28 trimestres, 4 bancos e 183 comarcas. Dentre as variáveis apresentadas, foi incluída em relação à tabela 2 o valor da leniência que cada banco enfrenta e que será explicada no capítulo seguinte.

6 Disponível em http://www.mpsp.mp.br/

7 Foram considerados o Banco do Brasil, Santander, Itaú Unibanco e Bradesco. A Caixa Econômica Federal foi excluída porque os litígios que a envolvem são de competência da Justiça Federal

8 Ver Coelho, Mello e Rezende (2013), Sanches, Junior e Srisuma (2018) e Joaquim e Doornik (2019) 
Tabela 2 - Estatística descritiva por comarca

\begin{tabular}{|c|c|c|c|c|c|c|}
\hline \multicolumn{7}{|l|}{ Comarcas incluídas } \\
\hline & Média & $\mathrm{DP}$ & Min & Mediana & Max & $\mathrm{N}$ \\
\hline Pró-devedor & 0.44 & 0.08 & 0.24 & 0.45 & 0.66 & 183 \\
\hline Sentenças por trimestre & 73.11 & 297.18 & 4.17 & 21.24 & $3,879.25$ & 183 \\
\hline Numero de varas & 3.53 & 6.11 & 1 & 3 & 81 & 183 \\
\hline $\begin{array}{l}\text { Máxima concentração } \\
\text { de decisões em um juiz } \\
\Delta \log (\text { Crédito })\end{array}$ & 0.53 & 0.19 & 0.12 & 0.53 & 0.99 & 183 \\
\hline entre trimestres & 0.01 & 0.01 & -0.03 & 0.01 & 0.04 & 183 \\
\hline \multicolumn{7}{|l|}{ Comarcas excluídas } \\
\hline & Média & $\mathrm{DP}$ & Min & Mediana & Max & $\mathrm{N}$ \\
\hline Pró-devedor & 0.47 & 0.11 & 0.17 & 0.47 & 0.78 & 136 \\
\hline Sentenças por trimestre & 8.45 & 6.10 & 1.17 & 6.51 & 30.54 & 136 \\
\hline Numero de varas & 1.25 & 0.47 & 1 & 1 & 3 & 136 \\
\hline $\begin{array}{l}\text { Máxima concentração } \\
\text { de decisões em um juiz } \\
\Delta \log (\text { Crédito })\end{array}$ & 0.86 & 0.12 & 0.45 & 0.90 & 1.00 & 136 \\
\hline entre trimestres & 0.005 & 0.03 & -0.04 & 0.004 & 0.22 & 136 \\
\hline
\end{tabular}

Nota: Os valores correspondem à média das observações trimestrais em cada comarca. As varas consideradas são apenas aquelas observadas na base de sentenças e não corresponde ao total de varas da comarca. Os resultados judiciais consideram instituições financeiras não incluídas na base de dados final.

Tabela 3 - Estatísticas descritivas dos dados finais

\begin{tabular}{|c|c|c|c|c|c|c|}
\hline & Média & $\mathrm{DP}$ & Min & Mediana & Max & $\mathrm{N}$ \\
\hline Pró-devedor & 0.45 & 0.33 & 0 & 0.5 & 1 & 14,062 \\
\hline $\begin{array}{l}\text { Sentenças por trimestre } \\
\text { por banco }\end{array}$ & 15.60 & 68.92 & 1 & 4 & 1,517 & 14,062 \\
\hline $\begin{array}{l}\text { Sentenças por trimestre } \\
\text { por comarca }\end{array}$ & 92.10 & 369.65 & 1 & 24 & 6,197 & 14,062 \\
\hline $\begin{array}{l}\text { Máxima concentração } \\
\text { de decisões em um juiz } \\
\text { Proporção de decisões }\end{array}$ & 0.50 & 0.23 & 0 & 0.5 & 1 & 14,062 \\
\hline $\begin{array}{l}\text { pelo juiz titular } \\
\text { Leniência observada } \\
\Delta \log (\text { Crédito })\end{array}$ & $\begin{array}{c}0.84 \\
-0.002 \\
0.01\end{array}$ & $\begin{array}{l}0.26 \\
0.06 \\
0.09\end{array}$ & $\begin{array}{c}0 \\
-0.44 \\
-1.68\end{array}$ & $\begin{array}{c}1 \\
-0.001 \\
0.01\end{array}$ & $\begin{array}{c}1 \\
0.48 \\
1.24\end{array}$ & $\begin{array}{l}14,062 \\
14,062 \\
14,062\end{array}$ \\
\hline
\end{tabular}


Nos dados finais, há grande heterogeneidade no número de decisões que cada comarca emite, como já era possível notar na tabela 2. Essa diferença ocorre pela grande variação no tamanho da estrutura judicial de cada comarca do estado, acompanhando o tamanho da população presente em cada região. Os valores muito distantes da mediana segue o comportamento dos dados agrupados por comarca, sendo que a capital do estado destoa em tamanho de população comparado com qualquer outra cidade - mais de nove vezes maior que a segunda cidade mais populosa. Para as demais variáveis, também é possível constatar que há grande variabilidade. Possíveis impactos relacionados a essa característica dos dados serão discutidas e avaliadas nas próxima seções. 


\section{Estimando o Impacto das Decisões Judici- ais Sobre a Oferta de Crédito}

\subsection{Modelo Básico}

Como observado em extensa literatura, mecanismos capazes de impor o cumprimento de acordos são fundamentais para garantir a existência de trocas. De forma ainda mais determinante, esse mecanismo é essencial quando a transferência de benefícios entre os agentes ocorrem de modo não simultâneo. Nesse contexto, o comportamento do poder judiciário, instituição responsável pela mediação de conflitos e competente para determinação do cumprimento de contratos, é incorporado na tomada de decisão dos agentes.

Com o fim de testar se instituições financeiras reagem caso decisões judiciais tendam a favorecer ou prejudica-las, o modelo abaixo é proposto.

$$
\Delta \log Y_{i c(t+1)}=\alpha_{t}+\gamma_{c}+\beta \operatorname{Prop}_{i c t}+u_{i c(t+1)}
$$

Onde $\Delta \log Y_{i c(t+1)}$ corresponde à variação do logaritmo do saldo de crédito do trimestre $t$ para o trimestre posterior $(t+1), i$ indica a instituição financeira observada e $c$ a respectiva comarca. A variável independente Propitc corresponde à proporção de sentenças proferidas contra o banco localizado na respectiva comarca e trimestre. Um conjunto completo de varáveis correspondentes a cada comarca e trimestre, $\gamma_{c}$ e $\alpha_{t}$, foram adicionadas à equação para controlar a heterogeneidade de características fixas não observáveis entre comarcas, além de choques comuns a todas as unidades de observação que venham a ocorrer em cada período.

A ideia central é que instituições financeiras observam o comportamento pró-credor ou pró-devedor do poder judiciário e escolhe, tudo mais constante, adequando-se ao risco devido às perdas em conflitos judiciais, se irá ser mais ou menos restritivo ao conceder crédito no período seguinte. Como cada instituição financeira enfrenta diferentes composições de juízes responsáveis pelas sentenças em seus processos, a proporção esperada de decisões contrarias ou a seu favor varia a cada período. A fonte de variação dos juízes responsáveis pelos processos de cada banco em cada período e comarca ocorre pela distribuição aleatória dos processos entre juízes de mesma comarca, além da frequente mudança de juízes entre jurisdições como resultado de preferencias locacionais de cada magistrado, promoções para comarcas maiores e tribunais superiores ou aposentadorias. Desse modo, podemos imaginar um processo de constante aprendizado do comportamento judicial por cada banco em cada 
comarca, em que as instituições financeiras ajustam para o período seguinte o saldo de crédito de acordo com a observação presente de um judiciário mais ou menos favorável a elas. Além disso, a determinação do nível de crédito disponível no período é dependente do saldo de crédito do período anterior, de forma que a observação do nível, ao invés da variação de crédito não sofreria alterações relevantes em períodos curtos. A intensidade de ajuste devido ao comportamento judicial aparenta ser uma medida mais razoável para captar o efeito que um judiciário mais favorável a alguma das partes gera no mercado de crédito.

O maior complicador em estimar a equação 4.1 é que, apesar de podermos identificar como a variação do saldo de crédito se relaciona com a proporção de decisões judiciais desfavoráveis às instituições financeiras, a simples estimação por mínimo quadrados ordinários (MQO) resultará em valores enviesados devido à existência de fatores que são simultaneamente correlacionados às variáveis dos dois lados da equação. Um típico exemplo pode ser considerado pela mudança de condições econômicas que podem influenciar decisões judiciais, como mostra Ichiono, Polo e Rettore (2003) ao observarem as condições do mercado de trabalho e processos trabalhistas na Itália. Além disso, a estimação por MQO considera todas as decisões como importantes para a determinação do ajuste de crédito, sendo que a grande maioria delas de fato devem ter o resultado esperado pelo banco. Uma melhor análise pode ser feita se considerarmos apenas o efeito de decisões que sofrem alteração devido a terem sido julgados por juízes mais ou menos favoráveis ao banco. Para isso utilizaremos uma abordagem por variável instrumental como descrita em sequência.

\subsection{Abordagem por Variável Instrumental}

Visando manter a imparcialidade do juiz responsável pelo processo, o procedimento de distribuição processual entre os magistrados é aleatório em toda a estrutura judicial brasileira. Como as demandas de primeira instância são distribuídas e julgadas regionalmente de acordo com o foro competente estabelecidos em lei, temos que o processo que determina o juiz responsável ocorre de forma aleatória, condicional à região e período observado. Dado essa característica do poder judiciário, podemos medir a leniência relativa entre os juízes que atuam na mesma jurisdição.

Seguindo o estratégia similar a Kling (2006), Dahl, Kostøl e Mogstad (2014), Dobbie e Song (2015), Aizer e Doyle (2015) e Dobbie, Goldin e Yang (2018), construímos uma medida de leniência de forma que se adapte às especificidades do problema aqui enfrentado. Como os mesmos bancos são observados em diferentes comarcas ao longo de vários períodos de tempo, agregamos todas observações da base de sentenças judicias em relação ao foro, 
trimestre, juiz e instituição financeira ré no processo $^{1}$, que passa a ser considerada como uma única observação. Feito isso, calculamos a média de decisões pró-devedor, incluindo todos os períodos e foros que o juiz atuou e excluindo a própria observação em questão, como na equação abaixo.

$$
P_{j i f t}=\frac{\sum_{k=1}^{n_{j}} P D_{k}-P D_{j i f t}}{n_{j}-n_{j i f t}}
$$

Onde, novamente, os subscritos $i, f$ e $t$ referem-se à instituição financeira, foro e trimestre, respectivamente. $\mathrm{O}$ valor de $n_{j}$ corresponde ao total de sentenças emitidas pelo juiz $j$ e $n_{\text {jict }}$ representa o total de decisões ao agregarmos a base inicial por juiz, instituição financeira, comarca e trimestre. O numerador representa o total de decisões pró-devedor observada em toda a base menos aquelas consideradas na observação. No final temos uma medida da proporção de decisões contra instituições financeiras excluindo as decisões que compõem a própria observação.

Como os processos são distribuídos aleatoriamente apenas dentro do foro e o grupo de juízes e tipos de processos sofrem alterações ao longo do tempo, esta medida de proporção foi regredida contra um conjunto completo de variáveis correspondentes aos diversos foros interagidos com variáveis para cada ano de observação. Os resíduos da amostra são a medida de leniência, livre dos efeitos de foro e tempo, para cada observação, seguindo o procedimento realizado por Dahl, Kostøl e Mogstad (2014) e Dobbie, Goldin e Yang (2018).

$$
\begin{gathered}
P_{j i f t}=\lambda x_{f a}+\varepsilon_{j i f t} \\
\widehat{\varepsilon}_{j i f t}=P_{j i f t}-\widehat{\lambda} x_{f a}
\end{gathered}
$$

Por fim, como cada instituição financeira observa um conjunto de decisões emitidas por diferentes juízes, construímos a medida final de leniência observada por cada instituição, em cada trimestre e comarca, como a média dos resultados da equação 4.4, ponderados pela quantidade de processos que cada juiz participa no respectivo trimestre e comarca ${ }^{2}$ em que cada banco é réu na ação. Para melhor compreensão:

$$
z_{i c t}=\frac{\sum_{k=1}^{j} \widehat{\varepsilon}_{k i c t} n_{k i c t}}{\sum_{k=1}^{j} n_{k i c t}}
$$

1 Nesta etapa, consideramos todas as decisões da base, não apenas aquelas que utilizaremos nas análises posteriores.

2 Em razão de não identificarmos o saldo de crédito por foro, mas por comarca, neste momento consideraremos todas as observações dos diversos foros da comarca de São Paulo uma única unidade territorial. Para todos os demais foros, a sobreposição territorial com a comarca local é exata. 
De forma implícita, para não carregarmos na notação, temos que todas as observações de diferentes foros $f$ dentro da mesma comarca $c$ são somadas para cada instituição financeira $i$, trimestre $t$ e juiz $j$. Explicitamente, a equação cinco mostra a agregação, por média ponderada de quantos processos cada juiz foi responsável em cada comarca, trimestre e instituição financeira.

Superada a construção da nossa variável $z_{i c t}$, o problema proposto pode ser apresentado pelas seguintes equações:

$$
\begin{gathered}
\operatorname{Prop}_{i c t}=\delta_{t}+\rho_{c}+\pi z_{i c t}+\mu_{i c t} \\
\Delta \log Y_{i c(t+1)}=\phi_{t}+\zeta_{c}+\Theta \operatorname{Prop}_{i c t}+\eta_{i c(t+1)}
\end{gathered}
$$

As notações seguem as mesmas referências apresentadas anteriormente e nosso interesse é estimar consistentemente $\theta$ a partir da regressão de mínimos quadrados ordinários em dois estágios (MQO2) sendo a equação 4.6 o primeiro estágio e a equação 4.7 o segundo estágio. O parâmetro de interesse representa a taxa crescimento do saldo de crédito no trimestre posterior à observação da proporção de decisões tomadas contrárias às instituições financeiras devido ao julgamento das ações terem ocorrido por um grupo de juízes com diferentes níveis de leniência.

\subsection{Validade do Instrumento e LATE}

A estratégia de identificação no contexto de variável instrumental depende de alguns pressupostos. Nesta seção discutiremos a validade do instrumento proposto e a interpretação dos resultados provenientes desta estratégia. Apresentaremos evidências de que o instrumento satisfaz as hipóteses de independência, restrição de exclusão, que é um instrumento forte e que seu efeito sobre nossa variável independente do segundo estágio ocorre de forma monotônica. Satisfeitas essas condições, podemos interpretar o estimador de variável instrumental como local average treatment efect (LATE) (ANGRIST; IMBENS; RUBIN, 1996).

Independência e restrição de exclusão: Para que o estimador de variável instrumental seja válido, precisamos estabelecer a hipótese de que a leniência observada pelas instituições financeiras afeta a variação de crédito unicamente através da proporção de decisões pródevedor observadas. Como argumentamos na seção anterior, a definição do juiz responsável pelo processo busca evitar a possibilidade de escolha do magistrado por quaisquer das partes envolvidas no processo. Desse modo, o nível de viés judicial enfrentado em cada processo tende a ser aleatório dentro de cada comarca. Para corroborar com esta hipótese, a tabela 4 apresenta que, apesar das instituições financeiras afetarem a variável independente, 
as mesmas não estão correlacionadas com o nível de leniência observada pela composição de juízes responsáveis pelos seus processos. Ou seja, instituições financeiras observam diferentes resultados em seus julgamentos, mas não têm capacidade de escolher, pelo menos de forma sistemática, juízes menos lenientes nos processos que enfrenta.

Tabela 4 - Teste de aleatorização na distribuição de processos

\begin{tabular}{lcc}
\hline \hline & $\begin{array}{c}\text { Pró-Devedor } \\
(1)\end{array}$ & $\begin{array}{c}\text { Leniência Observada } \\
\text { Bradesco }\end{array}$ \\
& $\begin{array}{c}-0.069^{* * *} \\
(0.007)\end{array}$ & 0.001 \\
& & $(0.001)$ \\
Itaú Unibanco & $-0.180^{* * *}$ & 0.001 \\
& $(0.007)$ & $(0.001)$ \\
& & \\
Santander & $-0.110^{* * *}$ & 0.001 \\
& $(0.007)$ & $(0.001)$ \\
comarca x ano & Sim & Sim \\
Estatística F & 212.8 & 0.367 \\
p-valor & {$[0.000]$} & {$[0.779]$} \\
$N$ & 14,062 & 14,062 \\
\hline \hline
\end{tabular}

Nota: A variável omitida da regressão foi referente ao Banco do Brasil. As estatísticas F reportadas são do teste conjunto da hipótese nula para as variáveis referentes aos Bancos. ${ }^{* * *} p<0.01,{ }^{* *} p<0.05,{ }^{*} p<0.1$

A tabela 4 sugere que a distribuição de processos ocorre de maneira aleatória entre os juízes da comarca em cada ano. Os coeficientes da coluna 2 não são estatisticamente insignificantes, seja individualmente ou conjuntamente, como o baixo valor da estatística F sugere. Entretanto, se existe algum outro canal em que a leniência dos juízes afeta o mercado de crédito que não seja pelos resultados das próprias sentenças, mas também correlacionado a esses, a interpretação de nosso estimador de MQO2 se torna frágil pois o coeficiente estimado estaria incorporando o efeito desse outro canal. Como a validade desta hipótese não é verificável, tomamos como uma suposição razoável para o restante do trabalho que a restrição de exclusão é válida. Além disso, a tabela 5 apresenta os resultados da forma reduzida, condição necessária para verificarmos que o instrumento proposto exerce impacto sobre a variável dependente.

Nos resultados da tabela 5, como em todas os outros resultados do trabalho, os erros padrão foram clusterizados a nível de comarca. Observamos que a leniência observada pelas instituições financeiras de fato exercem impacto sobre a taxa de variação de crédito. Verificase que a estabilidade dos resultados para diversos tipos de especificações corroboram com as evidências de independência da mesma. Ou seja, o nível de leniência enfrentado por cada 
Tabela 5 - Forma reduzida

\begin{tabular}{lcccc}
\hline \hline & \multicolumn{4}{c}{$\Delta \log$ crédito } \\
& $(1)$ & $(2)$ & $(3)$ & $(4)$ \\
\hline Leniência Observada & $-0.027^{* *}$ & $-0.027^{* *}$ & $-0.027^{*}$ & $-0.029^{* *}$ \\
& $(0.013)$ & $(0.013)$ & $(0.014)$ & $(0.014)$ \\
& & & & \\
Instituição Financeira & Não & Sim & Sim & Sim \\
Comarca x Ano & Não & Não & Sim & Sim \\
Controles Adicionais & Não & Não & Não & Sim \\
$N$ & 14,062 & 14,062 & 14,062 & 14,062 \\
\hline \hline
\end{tabular}

Nota: Erros padrões apresentados foram clusterizados a nível de comarca. Controles adicionais utilizados foram (todos em observações trimestrais por comarca): o total de sentenças observadas por cada instituição financeira; a quantidade de sentenças emitidas contra todos os bancos; a proporção de decisões proferidas por juízes titulares observada por cada banco ; e proporção decisões emitidas pelo juiz que mais proferiu sentenças na comarca. ${ }^{* * *} p<0.01,{ }^{* *} p<0.05,{ }^{*} p<0.1$

banco em cada período não é correlacionado a variáveis que se relacionam com alterações da taxa de variação de crédito.

Força do instrumento: Para mitigação do viés apresentado em estimações de MQO2, a verificação da força do instrumento utilizado no primeiro estágio é imprescindível para credibilidade dos resultados. A tabela 6 apresenta os resultados da estimação da equação 4.6.

Tabela 6 - Primeiro Estágio

\begin{tabular}{lcccc}
\hline \hline & \multicolumn{4}{c}{ Pró-Devedor } \\
& $(1)$ & $(2)$ & $(3)$ & $(4)$ \\
\hline Leniência Observada & $0.332^{* * *}$ & $0.338^{* * *}$ & $0.326^{* * *}$ & $0.322^{* * *}$ \\
& $(0.064)$ & $(0.064)$ & $(0.066)$ & $(0.066)$ \\
& & & & \\
Instituição Financeira & Não & Sim & Sim & Sim \\
Comarca x Ano & Não & Não & Sim & Sim \\
Controles Adicionais & Não & Não & Não & Sim \\
Estatística F Efetiva & {$[26.82]$} & {$[28.26]$} & {$[24.08]$} & {$[23.79]$} \\
$N$ & 14,062 & 14,062 & 14,062 & 14,062 \\
\hline \hline
\end{tabular}

Nota: Erros padrões apresentados foram clusterizados a nível de comarca. Controles adicionais utilizados foram (todos em observações trimestrais por comarca): o total de sentenças observadas por cada instituição financeira; a quantidade de sentenças emitidas contra todos os bancos; a proporção de decisões proferidas por juízes titulares observada por cada banco ; e proporção decisões emitidas pelo juiz que mais proferiu sentenças na comarca. ${ }^{* * *} p<0.01,{ }^{* *} p<0.05,{ }^{*} p<0.1$

Seguindo recomendação de Andrews, Stock e Sun (2019) utilizamos a estatística F proposta por Olea e Pflueger (2013) robusto a heterocedasticidade, autocorrelação e clusterização quando há apenas um regressor endógeno. $\mathrm{O}$ valores da estatística $\mathrm{F}$ variando 
entre 23,79 e 28,26 para todas as especificações nos garantem a presença de instrumentos fortes no primeiro estágio, o que reduz a preocupação em o estimador de MQO2 possuir alto viés e com possíveis problemas de inferência que pudessem surgir caso contrário.

Monotonicidade: Além das condições anteriores que asseguram a identificação correta da estimação por variável instrumental, para que possamos interpretar nosso estimador de MQO2 como LATE, o impacto da leniência observada pelas instituições financeiras sobre a proporção de decisões pró-devedor deve ser monotônica ao longo de todas as observações. A figura 1 apresenta uma evidência visual de que tal hipótese é válida para o caso estudado.

\section{Figura 1 - Primeiro Estágio}

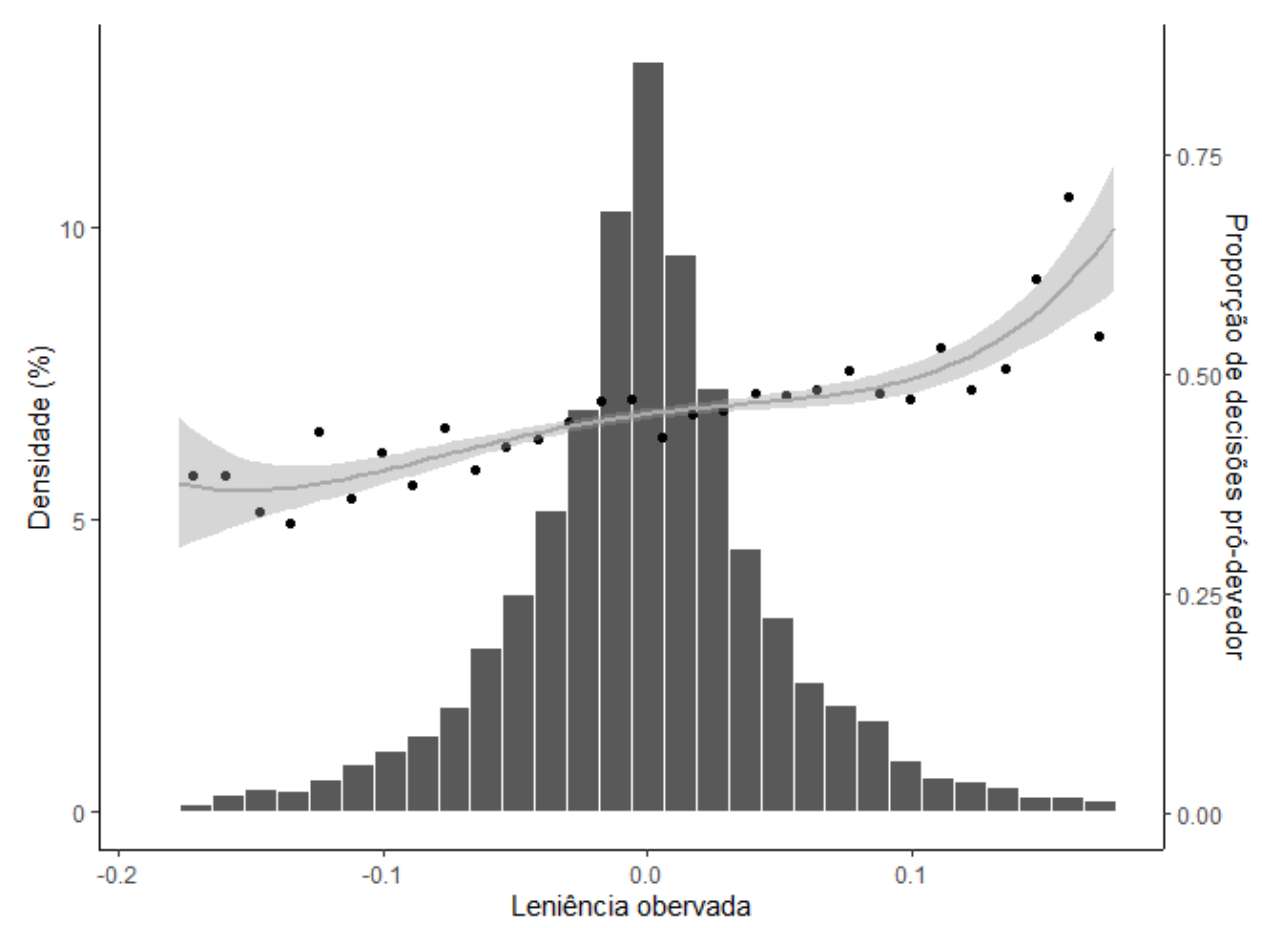

O histograma representa a frequência em que instituições financeiras se depararam com cada nível de leniência ao longo de todos os períodos. Os pontos mostram a proporção pró-credor de decisões dado o nível de leniência observada. A linha representa uma regressão polinomial de quarto grau de nosso instrumento contra nossa variável independente. Os limites em torno da linha de regressão representam os intervalos de confiança de $95 \%$. Observações referentes aos $1 \%$ maiores e menores nível de leniência observada foram excluídos.

A condição de monotonicidade implica que uma instituição financeira, ao se deparar com um dado nível de leniência devido ao conjunto de juízes responsáveis por seus processos, sempre observariam resultados menos favoráveis caso a leniência observada fosse maior. Tal condição satisfeita implica que o resultado do estimador de variável instrumental representa um LATE bem comportado em que a soma dos pesos para o cálculo do efeito 
médio do tratamento é igual a um.

Interpretando o LATE: A interpretação do LATE no contexto do trabalho é o efeito médio sobre a taxa de variação de crédito dos bancos ao observarem uma proporção de decisões judicias que se alteraria caso se deparassem com outro nível de leniência judicial. Ou seja, como mostram Angrist, Imbens e Rubin (1996), é o efeito médio do tratamento sobre os compliers. Dessa forma, o LATE é justamente o efeito do viés judicial sobre o mercado de crédito. O estimador de MQO2, satisfeitas as hipóteses apresentadas, nos mostra como o banco reage alterando a oferta de crédito no período seguinte ao observarem uma proporção diferente de decisões pró-devedor devido ao fato de seus processos terem sido julgados por juízes mais ou menos lenientes. 


\section{Resultados}

\subsection{Resultados Principais}

Nesta seção discutiremos os resultados encontrados a partir da estratégia adotada no capitulo anterior. Em todos os resultados os erros padrão foram clusterizados a nível de comarca para considerar a possível correlação entre bancos sob a mesma estrutura jurisdicional e possível correlação entre períodos. Os "controles adicionais"utilizados em algumas especificações correspondem a observações trimestrais, por comarca: do número de sentenças observadas por cada instituição financeira; do total de sentenças que todos os bancos observam; da proporção de decisões julgadas por juízes titulares nos processos de cada banco; e da proporção de decisões emitidas pelo juiz que mais proferiu sentenças na comarca (concentração de decisões em um único juiz). Tais variáveis de controle correspondem a resultados judiciais que variam entre períodos e comarcas e que potencialmente poderiam estar correlacionadas ao nível de viés observado pelos bancos e também estar influenciando o crédito disponibilizado pelas instituições financeiras. Para considerar a heterogeneidade entre bancos pelo perfil de cliente, tipo de crédito, atuação de mercado, entre outros fatores que poderiam influenciar nosso resultado, especificações com variáveis correspondentes aos bancos foram incluídas. Da mesma forma controlamos para a interação entre comarca e ano, de modo que levamos em consideração possíveis alterações nos tipos de processos e composição dos magistrados das comarcas ao longo de diferentes anos.

Para o modelo simples da equação 4.1, a tabela 7 nos mostra que não há correlação evidente entre a proporção de decisões pró-devedor em processos movidos contra instituições financeiras e a taxa de variação de crédito no período seguinte. Para todas as especificações encontramos resultados próximos a zero e estatisticamente insignificantes. Ou seja, os bancos que observam mais decisões contrarias a ele, em média, não alteram a oferta de crédito em proporção diferente dos bancos mais beneficiados pela justiça. Entretanto, esses resultados não são conclusivos.

Possíveis fontes de endogeneidade podem surgir por variáveis econômicas que afetam simultaneamente o mercado de crédito e as decisões judiciais, seja por seleção dos processos que acabam em julgamento ou por afetar diretamente como os juízes decidem. Além disso, podemos imaginar, por exemplo, que, devido ao retorno elevado dos contratos que sofrem maiores riscos de perdas judiciais, um banco esteja disposto a observar mais derrotas. Dessa forma, quando se assina um contrato, o banco já considera a probabilidade de perder judicialmente e, portanto, a simples proporção total de decisões pró-devedor, se antecipadas no universo total de processos, não gera impacto sobre oferta de crédito no 
Tabela 7 - Modelo Simples MQO

\begin{tabular}{lcccc}
\hline \hline & \multicolumn{4}{c}{$\Delta \log ($ crédito $)$} \\
& $(1)$ & $(2)$ & $(3)$ & $(4)$ \\
\hline Pró-Devedor & -0.002 & -0.001 & 0.001 & 0.001 \\
& $(0.002)$ & $(0.003)$ & $(0.003)$ & $(0.003)$ \\
instituição financeira & Não & Sim & Sim & Sim \\
comarca x ano & Não & Não & Sim & Sim \\
controles adicionais & Não & Não & Não & Sim \\
$N$ & 14,062 & 14,062 & 14,062 & 14,062 \\
\hline \hline
\end{tabular}

Nota: Erros padrões apresentados foram clusterizados a nível de comarca. Controles adicionais utilizados foram (todos em observações trimestrais por comarca): o total de sentenças observadas por cada instituição financeira; a quantidade de sentenças emitidas contra todos os bancos; a proporção de decisões proferidas por juízes titulares observada por cada banco ; e proporção decisões emitidas pelo juiz que mais proferiu sentenças na comarca. ${ }^{* * *} p<0.01,{ }^{* *} p<0.05,{ }^{*} p<0.1$

período seguinte.

Dessa forma, como foi apresentado no capitulo anterior, a estratégia via variável instrumental nos apresenta um meio de identificação e interpretação causal de como decisões judiciais que sofrem influência em seu resultado devido a diferentes níveis de leniência judicial impactam o mercado de crédito. Primeiramente, como propomos um instrumento calculado pela leniência de cada juiz responsável pelas sentenças de cada banco, período e comarca, ponderada pelo total de decisões que cada um foi responsável, devemos observar novamente a tabela 6 para interpretarmos o primeiro estágio do modelo. Para todas as especificações temos que um aumento de leniência em um desvio padrão eleva em aproximadamente 2 pontos percentuais de decisões perdidas pelos bancos. Apesar de não aparentar um resultado de grande magnitude, temos que é estatisticamente significante a $1 \%$. Devemos lembrar que a diferença de leniência observada tende a zero quão maior o número de processos no período e menor o número de juízes. À medida que cresce a quantidade processos e diminui total de juízes na comarca, os bancos tendem a ter a mesma quantidade de processos julgados por cada juiz. Possivelmente este é o ponto em que reside a maior fragilidade do desenho de pesquisa. Por esse fato, a alta concentração bancária brasileira pelas instituições analisadas fazem com que a variabilidade do instrumento convirja a zero nessas condições. De toda forma, como já foi apresentado, existe, apesar de relativamente baixa, variabilidade na leniência observada entre bancos e ela é estatisticamente significante ao explicar os resultados judiciais. Pela tabela 5 observamos que, de fato, valendo independência, existem evidências de efeito causal do instrumento proposto na taxa de variação de crédito dos bancos para o período seguinte. A um nível de significância de 5\%, pela coluna 1 da mesma tabela, temos que o aumento em um desvio padrão na leniência observada do conjunto de juízes responsáveis pelos processos impacta 
negativamente, em média, a taxa de variação de crédito do trimestre seguinte em 1,6 pontos percentuais. Os resultados se mantém praticamente constantes para especificações das colunas 2 a 4 .

Finalmente, os principais resultados do trabalho estão reportados na tabela 8 . Observamos efeitos economicamente significantes que mostram que a variação de 1 ponto percentual de acréscimo na proporção de sentenças pró-devedor gera uma taxa de crescimento no saldo de crédito aproximadamente 0,08 pontos percentuais menor. Para melhor compreensão, temos que o aumento de 1 desvio padrão na proporção de decisões contrárias às instituições financeiras reduz o equivalente a aproximadamente 3 pontos percentuais na taxa de variação do saldo de crédito para o período posterior. Ou o equivalente a 0,38 desvio padrão na taxa de variação observada em toda a amostra considerando o resultado da especificação mais completa da coluna 4. Também observa-se que para as quatro especificações os resultados se mantém estáveis, corroborando com mais evidências de que nossos resultados estão sendo direcionados pela variável instrumental proposta. Para as especificações das colunas 1,2 e 4, os resultados são significantes a 5\%, enquanto que para a especificação da coluna 3 , o p-valor do coeficiente de interesse é ligeiramente superior a 0,05 .

Tabela 8 - Mínimos Quadrados em Dois Estágios

\begin{tabular}{lcccc}
\hline \hline & \multicolumn{4}{c}{$\Delta \log ($ crédito $)$} \\
& $(1)$ & $(2)$ & $(3)$ & $(4)$ \\
\hline Pró-Devedor & $-0.082^{* *}$ & $-0.079^{* *}$ & $-0.082^{*}$ & $-0.089^{* *}$ \\
& $(0.040)$ & $(0.039)$ & $(0.044)$ & $(0.045)$ \\
Instituição Financeira & Não & Sim & Sim & Sim \\
Comarca x Ano & Não & Não & Sim & Sim \\
Controles Adicionais & Não & Não & Não & Sim \\
$N$ & 14,062 & 14,062 & 14,062 & 14,062 \\
\hline \hline
\end{tabular}

Nota: Erros padrões apresentados foram clusterizados a nível de comarca. Controles adicionais utilizados foram (todos em observações trimestrais por comarca): o total de sentenças observadas por cada instituição financeira; a quantidade de sentenças emitidas contra todos os bancos; a proporção de decisões proferidas por juízes titulares observada por cada banco ; e proporção decisões emitidas pelo juiz que mais proferiu sentenças na comarca. ${ }^{* * *} p<0.01,{ }^{* *} p<0.05,{ }^{*} p<0.1$

Dada a possibilidade de instrumentos fracos, mesmo com a estatística $\mathrm{F}$ sendo alta, temos que o potencial viés apresentado pela estimação por MQO2 estaria subestimando o real efeito. Se esse for o caso, estaremos aproximando o resultado em direção aos valores da estimação por MQO apresentados na tabela 7.

Fica claro o relevante impacto econômico uma vez que o simples fato de ser julgado por magistrados que diferem em intensidade de leniência ao credor é responsável por 
expressiva variação na taxa de crescimento do crédito dessa instituição financeira. Como discutido anteriormente, o resultado é interpretado como LATE. Esse é o efeito médio que a discricionariedade que um grupo de juízes, levando em consideração o conjunto de suas tendências em favorecer credores ou devedores, causa sobre a disponibilidade de crédito futuro através do resultado de suas sentenças. Portanto, o estimador de MQO2 encontrado não se limita à simples confirmação do resultado da regressão simples por algum tipo de variação exógena que altere a variável independente, mas, de fato, pode ser interpretado como a resposta fundamental deste trabalho.

Esses resultados são compatíveis com a literatura teórica e empírica que mostram que a capacidade do judiciário em garantir o cumprimento de contratos e recuperação de garantias é responsável por proporcionar uma maior oferta de crédito. Considerando que a perda de disputas judiciais reflete em um menor enforcement observado, é esperado menores taxas de crescimento na disponibilidade de crédito por instituições financeiras que observam maiores riscos. A literatura teórica também prevê que os agentes, ao internalizarem maiores riscos associados ao nível de viés do sistema judiciários, buscam contratos menos contingentes, ou seja, que dependam de menor discricionariedade do juiz para verificar estados da natureza ambíguos. Desta forma, modalidades de contrato que estejam mais sujeitos a manifestação do viés do juiz sofrem limitações em detrimento a contratos que minimizam a ação de interpretação judicial. Esse mecanismo pode ser responsável por limitar as opções de financiamento disponíveis, gerando menor demanda por empréstimos dada a restrição de contratos ofertados observada.

Por fim, como os resultados apresentados aproveitam da heterogeneidade nas preferências dos juízes dentro de cada comarca, podemos imaginar que no limite não existiriam bancos favorecidos ao longo do tempo. Ou seja, todos os bancos enfrentariam maiores e menores vieses judiciais ao longo de períodos distintos, dentro da mesma comarca, mas em um tempo longo o suficiente observariam um nível similar de viés de toda estrutura judicial e se adequariam ao nível médio de leniência sem responder a tais variações. De fato, poderíamos argumentar que a mudança de magistrados, leis, entendimentos de tribunais superiores sempre são fontes de variação das expectativas quanto à atuação judicial, fazendo com que os bancos estejam em constante aprendizado de como o judiciário local decide. Mesmo assim, apesar da fluidez do direito brasileiro, tais variações não tenderiam a beneficiar nenhum dos bancos dentro da mesma comarca (pelo menos através do nível de leniência que os juízes responsáveis por seu processos apresentam), fazendo com que as características jurisdicionais de cada região, e não a individualidade dos magistrados, seja o fator determinante para o nível de crédito local. Certamente este trabalho não responde a esse problema, mas em seus méritos apresenta evidências robustas de que a discricionariedade dos juízes introduzidas em cada decisão determinam o comportamento do mercado de crédito local. Ou seja, mesmo que a heterogeneidade entre juízes não determine 
que um banco oferte mais ou menos crédito que outro dentro da mesma jurisdição no longo prazo, temos evidências de que instituições financeiras reagem às decisões que as favorecem ou prejudiquem devido ao tipo de juiz responsável pelo seu processo no curto prazo. Dessa forma, espera-se que uma comarca composta por juízes com tendência geral pró-banco ou pró-devedor impactará o mercado de crédito de forma ampla.

\subsection{Outros Resultados e Robustez}

De forma a confirmar os resultados da seção anterior, apresentaremos exercícios que objetivam corroborar com as evidências à pouco discutidas. Para isso, iniciamos excluindo observações com valores extremos correspondentes ao primeiro e último percentil de leniência observada pelos bancos. Tais observações ocorrem com baixa frequência e podem conduzir a resultados direcionados por observações improváveis de ocorrem. A tabela 9 apresenta os resultados principais deste novo conjunto de informações.

Tabela 9 - Resultados Eliminando 1\% dos Maiores e Menores Valores de Leniência

\begin{tabular}{lcccc}
\hline \hline & \multicolumn{4}{c}{$\Delta \log ($ crédito $)$} \\
& $(1)$ & $(2)$ & $(3)$ & $(4)$ \\
\hline Pró-Devedor & $-0.107^{* * *}$ & $-0.106^{* * *}$ & $-0.110^{* *}$ & $-0.119^{* *}$ \\
& $(0.039)$ & $(0.038)$ & $(0.046)$ & $(0.048)$ \\
& & & & \\
Instituição Financeira & Não & Sim & Sim & Sim \\
Comarca x Ano & Não & Não & Sim & Sim \\
Controles Adicionais & Não & Não & Não & Sim \\
$N$ & 13,780 & 13,780 & 13,780 & 13,780 \\
\hline \hline
\end{tabular}

Nota: Erros padrões apresentados foram clusterizados a nível de comarca. Controles adicionais utilizados foram (todos em observações trimestrais por comarca): o total de sentenças observadas por cada instituição financeira; a quantidade de sentenças emitidas contra todos os bancos; a proporção de decisões proferidas por juízes titulares observada por cada banco ; e proporção decisões emitidas pelo juiz que mais proferiu sentenças na comarca. ${ }^{* * *} p<0.01,{ }^{* *} p<0.05,{ }^{*} p<0.1$

Qualitativamente os resultados se mantém aos reportados anteriormente que utilizam toda a base. Entretanto, há um aumento de magnitude dos coeficientes e evidências mais fortes para se rejeitar a hipótese nula. A diferença nos valores da tabela 8 e tabela 9 são direcionados por um primeiro estágio mais forte. Os valores extremos, que apresentam pouca probabilidade de ocorrência, atenuam o poder explicativo do nosso instrumento sobre a variável independente do segundo estágio. Tal fato ocorre por representarem situações com poucas observações que juízes muito lenientes decidiram a favor do banco em um processo que seria favorável independentemente do magistrado designado e vice-versa. Dessa forma, encontramos resultados mais robustos ao eliminar ruídos gerados por essas observações. 
O próximo exercício é motivado pela discussão realizada na secção anterior. Comarcas que julgam uma grande quantidade de processos tendem a não apresentar variação na leniência observada entre bancos e períodos. Além disso, em poucos períodos já é possível a instituição financeira ter conhecimento do nível de leniência geral da comarca. Se isso ocorre, os resultados encontrados devem aparecer de forma mais acentuada em comarcas menores do que nas maiores. A figura 2 nos mostra que comarcas com grande quantidade média de processos por trimestre apresentam valores para o instrumento com pouca variabilidade entre bancos e períodos e próximos a zero. Nos gráficos, os eixos horizontais representam a média de sentenças observadas na amostra, por comarca, em cada período e para todos os bancos, enquanto os eixos verticais representam os valores da variância do instrumento referente a todas as observações segregadas por comarca.

Pelo gráfico da figura 3(a), fica claro que comarcas com mais processos apresentam valores para o instrumento utilizado próximo de zero, como foi especulado anteriormente. Ao longo dos gráficos (a) a (e) da mesma figura, observa-se que ao excluirmos comarcas com mais processos, a variação nos valores do instrumento aumenta dentro e entre comarcas. Caso a hipótese levantada de que os resultados estão sendo direcionadas por comarcas menores por existir variabilidade no nível de leniência judicial enfrentado por cada banco, o que não se observa em comarcas maiores, devemos encontrar resultados de maior magnitude ao restringirmos o estudo para esses regiões. A tabela 10 apresenta os resultados de um exercício motivado por essas hipóteses.

Tabela 10 - Subamostra Excluindo as Maiores Comarcas

\begin{tabular}{lccccc}
\hline \hline & \multicolumn{5}{c}{$\Delta \log ($ crédito $)$} \\
& $(1)$ & $(2)$ & $(3)$ & $(4)$ & $(5)$ \\
\hline Pró-Devedor & $-0.089^{* *}$ & $-0.093^{* *}$ & $-0.105^{*}$ & $-0.126^{* *}$ & $-0.170^{*}$ \\
& $(0.046)$ & $(0.047)$ & $(0.057)$ & $(0.063)$ & $(0.091)$ \\
& & & & & \\
Instituição Financeira & $\mathrm{Sim}$ & $\mathrm{Sim}$ & $\mathrm{Sim}$ & $\mathrm{Sim}$ & $\mathrm{Sim}$ \\
Comarca x Ano & $\mathrm{Sim}$ & $\mathrm{Sim}$ & $\mathrm{Sim}$ & $\mathrm{Sim}$ & $\mathrm{Sim}$ \\
Controles Adicionais & $\mathrm{Sim}$ & $\mathrm{Sim}$ & $\mathrm{Sim}$ & $\mathrm{Sim}$ & $\mathrm{Sim}$ \\
Número de Comarcas & 183 & 163 & 143 & 123 & 103 \\
$N$ & 14,062 & 12,166 & 10,337 & 8,528 & 6,808 \\
\hline \hline
\end{tabular}

Seguindo a lógica apresentada nos gráficos, a tabela 10 mantém a ordem de exclusão de comarcas, de (a) a (e) da figura 2, nas regressões das colunas (1) a (5). O resultado da regressão ao considerarmos as 103 comarcas com menores médias de processos por trimestre é quase o dobro do resultado inicial. Também constata-se que o comportamento é sempre em direção a efeitos maiores quão mais restrito a comarcas menores estamos observando. Esses resultados também demonstram que devido a limitações no desenho de 
pesquisa proposto, não é possível obtermos evidências claras sobre como os bancos reagem ao viés judicial em comarcas maiores. Nessas, não há variabilidade do viés observado por cada banco para que possamos comparar seus respectivos comportamentos quanto à expansão ou retração de crédito. Porém, esses novos resultados nos apresentam evidências ainda mais robustas de que locais em que conseguimos observar instituições financeiras enfrentando distintos níveis de leniência judicial comportam-se de maneiras diferentes e no sentido do que se esperava inicialmente. Os resultados paras as subamostras reafirmam a conclusão do resultado geral.

Outra preocupação que surge em estratégias de identificação baseadas em variáveis instrumentais é quanto à força do instrumento. Apesar da possibilidade de presença de viés na estimação esteja subestimando nosso resultado, como já foi discutido, possíveis problemas de inferência podem surgir caso estejamos lidando com esta situação. A tabela 11 reúne os valores para o intervalo de confiança baseados na estatística de teste de AndersonRubin, robusta a instrumentos fracos e eficiente em casos simplesmente identificados. Como base para comparação, também é apresentado o intervalo de confiança convencional de Wald. Em ambos os casos consideramos a especificação mais completa referente à coluna (4) da tabela 8.

Tabela 11 - Intervalos De Confiança Robustos a Instrumentos Fracos

\begin{tabular}{cc}
\hline \hline Anderson-Rubin & {$[-0.197 ;-0,008]$} \\
Wald & {$[-0.174 ;-0.004]$} \\
\hline \hline
\end{tabular}

Nota: Intervalos de confiança para o estimador de MQO2 a nível de significância de $5 \%$ referente à especificação mais completa das colunas (4) dos resultados apresentados utilizando toda a amostra.

O intervalo de confiança de Anderson-Rubin é valido na presença ou não de instrumentos fracos. Encontramos que esse não se altera significativamente em relação ao intervalo de confiança Wald. Esse resultado é consistente com a rejeição de instrumentos fracos devido à estatística F ser elevada (superior a 23,11 como proposto por Olea e Pflueger (2013)) e reforça as evidências para aceitarmos o instrumento como valido. 
Figura 2 - Variabilidade do Nível de Leniência por Tamanho de Comarca

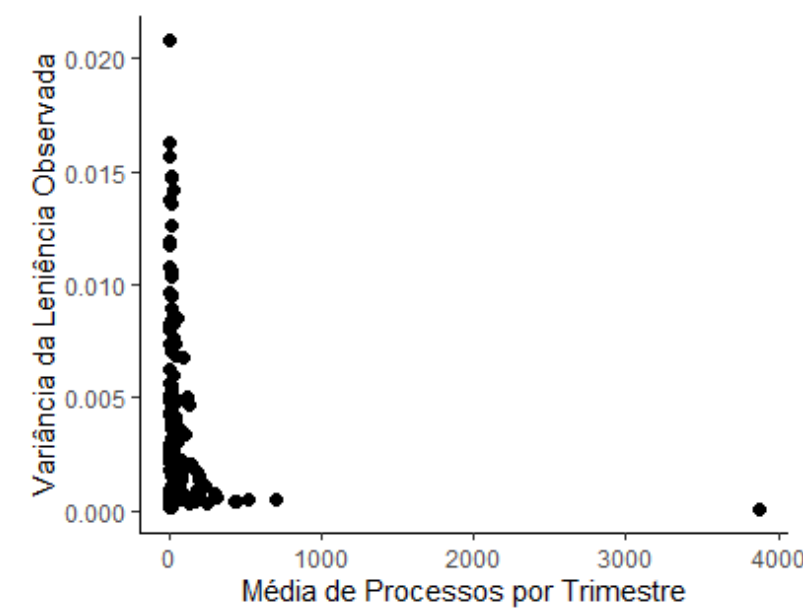

((a)) Todas as 183 Comarcas

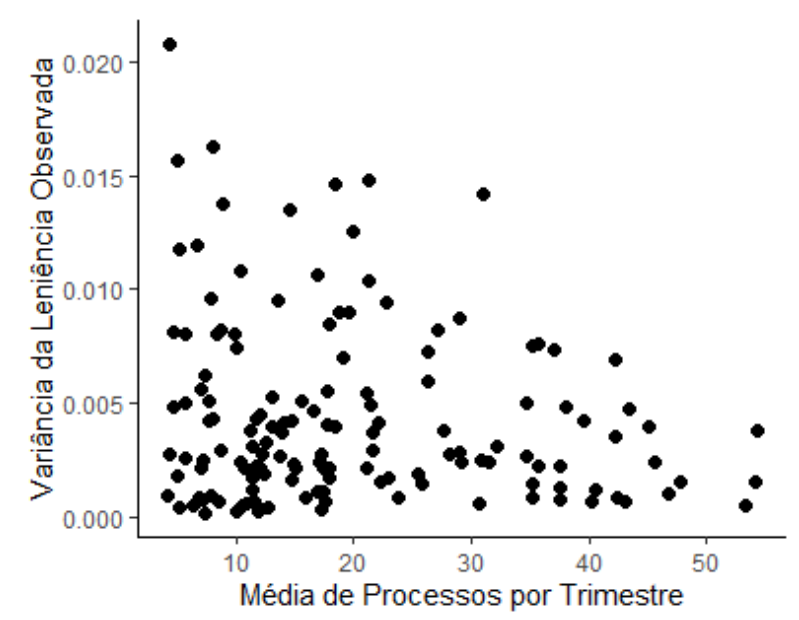

((c)) Excluindo as 40 Maiores Comarcas

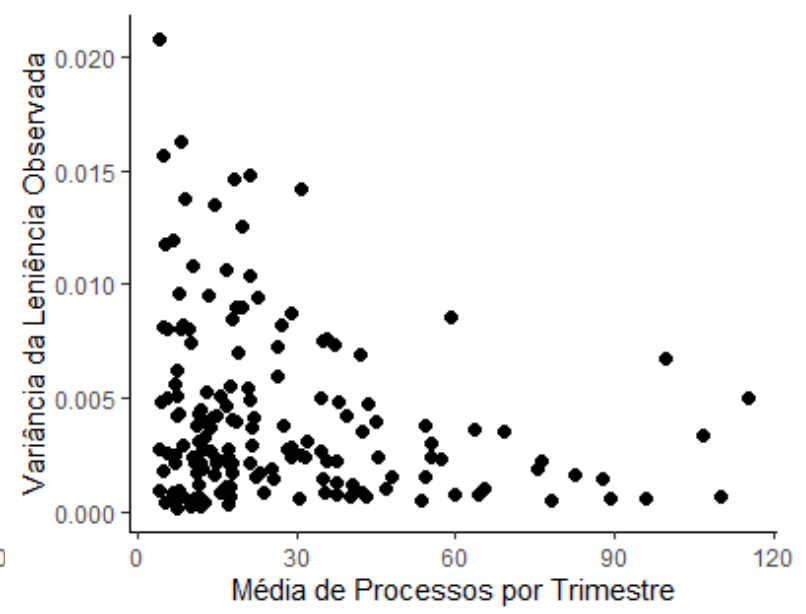

((b)) Excluindo as 20 Maiores Comarcas

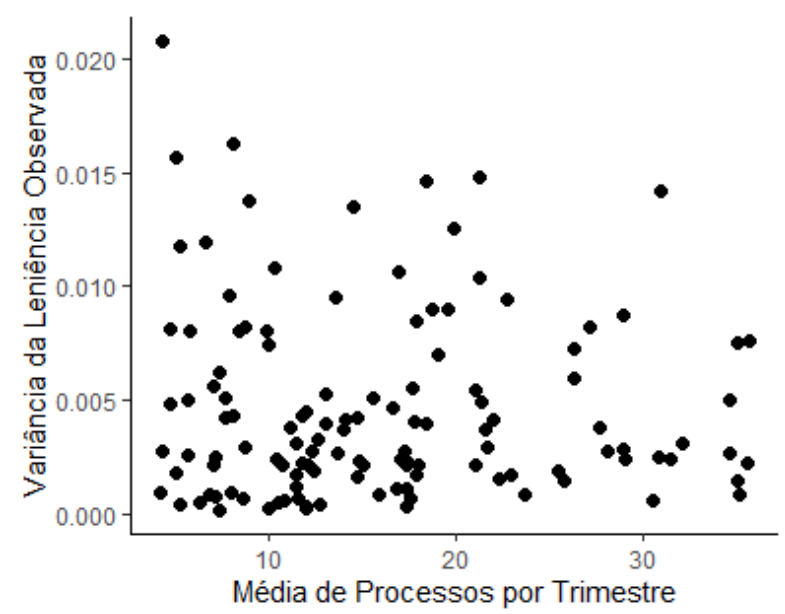

((d)) Excluindo as 60 Maiores Comarcas

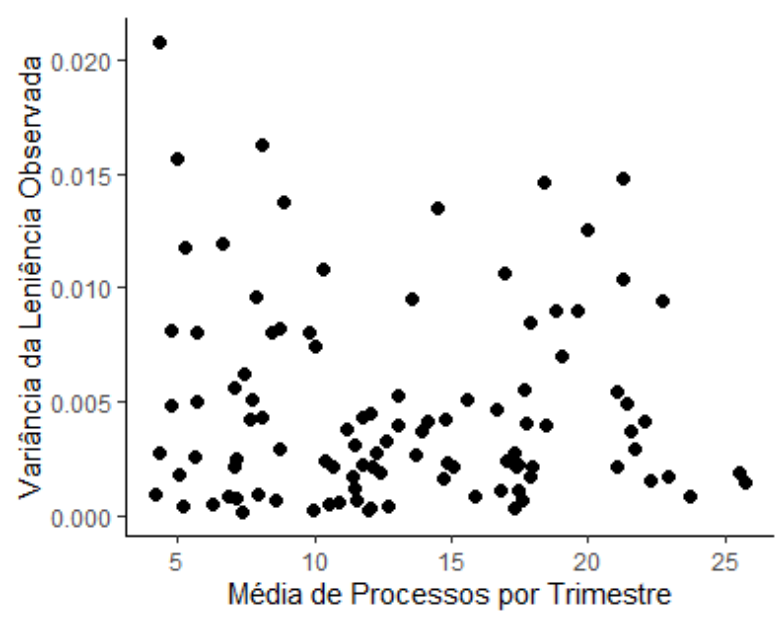

((e)) Excluindo as 80 Maiores Comarcas 


\section{Conclusão}

O presente trabalho estima o impacto que decisões judiciais em primeira instância causa sobre o mercado de crédito local. Encontramos que juízes mais lenientes são capazes de gerar efeitos negativos no mercado de crédito com significante relevância do ponto de vista econômico. Esses resultados corroboram com a literatura teórica e empírica uma vez que, considerando a discricionariedade judicial um mecanismo gerador de diferentes níveis de enforcement, instituições financeiras que perdem mais processos judiciais, por terem enfrentado juízes mais propensos em favorecer a parte devedora, reagem disponibilizando menor saldo de crédito no período seguinte do que as que enfrentam efeito contrário. Os resultados sugerem que a existência de margem para atuação dos magistrados sobre decisões que envolvam a relação entre credor e devedor pode ser um gerador de insegurança levando a restrição de crédito.

Não avaliamos o mérito das decisões, logo não há como definir se existe uma tendência de favorecimento geral a favor de credores ou devedores. Sequer podemos dizer se há descumprimento do ordenamento jurídico ao revelar a diferença de vieses entre juízes em prol de alguma das partes no processo. A análise se restringe a observar que instituições financeiras reagem a juízes mais ou menos lenientes, ampliando ou restringindo a oferta de crédito. Embora não tenhamos capacidade de saber quais decisões são ou não corretas do ponto de vista legal, o trabalho tem como mérito observar que o viés relativo enfrentado por cada instituição financeira é suficiente para implicar alterações em seu comportamento. Observamos que existe divergência entre decisões judiciais e que a busca por um sistema jurídico mais uniforme, seja por leis mais claras ou por limitação da atuação discricionárias dos magistrados, pode ser um caminho para ampliação do bem estar social.

A partir das evidências apresentadas nesse trabalho, uma possível extensão seria medir o impacto sobre a taxa de juros dos contratos de crédito fechados. A alteração na disponibilidade de crédito sugere que um mecanismo para que isto ocorra seja a alteração no preço do produto. Complementarmente, podemos imaginar que há alteração dos tipos de contratos fechados. Instituições financeiras que observam juízes mais favoráveis a elas estariam mais dispostas a ofertarem tipos de contratos mais contingentes. Futuras análises com informações mais detalhadas sobre cada tipo de contrato e informações mais completas a respeito dos processos são importantes para compreendermos melhor os diversos efeitos do fenômeno reportado por esse trabalho. 



\section{Referências}

AIZER, A.; DOYLE, J. J. Juvenile incarceration, human capital, and future crime: Evidence from randomly assigned judges. The Quarterly Journal of Economics, Oxford University Press, v. 130, n. 2, p. 759-803, 2015. Citado 2 vezes nas páginas 22 e 36.

ANDREWS, I.; STOCK, J.; SUN, L. Weak instruments in iv regression: Theory and practice. Annual Review of Economics. Forthcoming., 2019. Citado na página 40.

ANGRIST, J. D.; IMBENS, G. W.; RUBIN, D. B. Identification of causal effects using instrumental variables. Journal of the American Statistical Association, [American Statistical Association, Taylor Francis, Ltd.], v. 91, n. 434, p. 444-455, $1996 . \quad$ Citado 2 vezes nas páginas 38 e 42 .

ARAUJO, A.; FERREIRA, d. V. X. R. d. V. X.; FUNCHAL, B. The brazilian bankruptcy law experience. Journal of Corporate Finance, Elsevier, v. 18, n. 4, p. 994-1004, 2012. Citado na página 24.

ARIDA, P.; BACHA, E.; LARA-REZENDE, A. Inflation Targeting, Debt, and the Brazilian experience, 1999 to 2003: Credit, interests, and jurisdictional uncertanty: Conjetures on the case of brazil. [S.1.]: The MIT Press, 2005. Citado na página 21.

BANERJEE, A.; DUFLO, E. Growth theory through the lens of development economics. Handbook of Economic Growth 1, p. 473-552., 2005. Citado na página 21.

BHULLER, M. et al. Incarceration, recidivism and employment. Accepted in Journal of Political Economy, 2019. Citado na página 22.

CHANG, T.; SCHOAR, A. Judge specific differences in chapter 11 and firm outcomes. Revise and Resubmit at Journal of Finance, 2013. Citado 2 vezes nas páginas 22 e 23.

COELHO, C. A.; MELlO, J. M. D.; FUNCHAL, B. The brazilian payroll lending experiment. The Quarterly Journal of Economics, The MIT Press, v. 94, n. 4, p. 925-934, 2012. Citado na página 24.

COELHO, C. A.; MELlO, J. M. de; REZENDE, L. Do public banks compete with private banks? evidence from concentrated local markets in brazil. Journal of Money, Credit and Banking, v. 45, n. 8, p. 1581-1615, 2013. Citado na página 32.

COSTA, A. C. A.; MELLO, J. M. P. D. , judicial risk and credit market performance: Micro evidence from brazilian payroll loans (may 2006). nber working paper no. w12252. available at ssrn: https://ssrn.com/abstract=903890. 2006. Citado na página 24.

DAHL, G. B.; KOSTØL, A.; MOGSTAD, M. Family welfare cultures. The Quarterly Journal of Economics, Oxford University Press, v. 129, n. 4, p. 1711-1752, 2014. Citado 3 vezes nas páginas 22,36 e 37.

DJANKOV, S. et al. Debt enforcement around the world. Journal of Political, v. 116, n. 3, p. 1105-1150, 2008. Citado 2 vezes nas páginas 21 e 23. 
DOBBIE, W.; GOLDIN, J.; YANG, C. S. The effects of pretrial detention on conviction, future crime, and employment: Evidence from randomly assigned judges. American Economic Review, v. 108, n. 3, p. 201-240, 2018. Citado 3 vezes nas páginas 22, 36 e 37.

DOBBIE, W.; SONG, J. Debt relief and debtor outcomes: Measuring the effects of consumer bankruptcy protection. American Economic Review, v. 105, n. 3, p. 1272-1311, 2015. Citado 2 vezes nas páginas 22 e 36.

GENNAIOLI, N. Optimal contracts with enforcement risks. Journal of The European Economic Assossiation, v. 11, n. 1, p. 59-82, 2013. Citado na página 24.

GONçAlves, M. V. R. Direito Processual Civil Esquematizado. [S.l.]: Saraiva, 2017. Citado na página 26.

ICHIONO, A.; POLO, M.; RETTORE, E. Are judges biased by labor market conditions? European Economic Review, Elsevier, v. 1, n. 47, p. 913-944, 2003. Citado na página 36.

JAPPELLI, T.; PAGANO, M.; BIANCO, M. Courts and banks: Effects of judicial enforcement on credit markets. Journal of Money, Credit and Banking, Ohio State University Press, v. 37, n. 2, p. 223-244, 2005. Citado 2 vezes nas páginas 23 e 24.

JOAQUIM, G.; DOORNIK, B. van. Bank competition, cost of credit and economic activity: Evidence from brazil. Working paper, 2019. Citado na página 32.

KLING, J. R. Incarceration length, employment, and earnings. American Economic Review, v. 96, n. 3, p. 863-876, 2006. Citado 2 vezes nas páginas 22 e 36.

LAEVENA, L.; MAJNONI, G. Does judicial efficiency lower the cost of credit? Journal of Banking Finance, Elsevier, v. 29, n. 7, p. 1791-1812, 2005. Citado na página 23.

LEVINE, R. Finance and growth: Theory and evidence. Handbook of Economic Growth 1, p. 885-934, 2005. Citado na página 21.

MADEIRA, G. A. Legal enforcement, default and heterogeneity of project-financing contracts. Annals of Finance, v. 10, n. 4, p. 569-602, Nov 2014. Citado na página 24.

NORTH, D. C. Institutions, institutional change and economic performance. Cambrige University Press, v. 1, 1990. Citado na página 21.

OLEA, J. L. M.; PFLUEGER, C. A robust test for weak instruments. Journal of Business Economic Statistics, Cambridge University Press, v. 37, n. 1, p. 358-369, 2013. Citado 2 vezes nas páginas 40 e 49.

PASQUALOTTO, A. O código de defesa do consumidor em face do novo código civil. Revista de direito do Consumidor, v. 43, p. 96-110, 2002. Citado na página 25.

PINHEIRO, A. C. Judiciário, reforma e economia: A visão dos magistrados. IPEA, Texto para discussão No 11.25, 2003. Citado na página 21.

PONTICELLI, J.; ALENCAR, L. S. Court enforcement, bank loans, and firm investment: Evidence from a bankruptcy reform in brazil. The Quarterly Journal of Economics, Oxford University Press, v. 131, n. 3, p. 1365-1413, 2016. Citado 2 vezes nas páginas 23 e 24 . 
PORTA, R. L. et al. Legal determinants of external finance. The Journal of Finance, v. 52, n. 3, p. 1131-1150, 1997. Citado na página 21.

PORTA, R. L. et al. Law and finance. Journal of Political Economy, The University of Chicago Press, v. 106, n. 6, p. 113-1155, 1998. Nenhuma citação no texto.

SANCHES, F.; JUNIOR, D. S.; SRISUMA, S. Banking privatization and market structure in brazil: a dynamic structural analysis. The RAND Journal of Economics, v. 49, n. 4, p. 936-963, 2018. Citado na página 32.

VELlosO, C. M. Do poder judiciário: organização e competência. Revista de Direito Administrativo, v. 200, n. 0, p. 1-19, 1995. Citado na página 26.

VISARIA, S. Legal reform and loan repayment: The microeconomic impact of debt recovery tribunals in india. American Economic Journal: Applied Economics, v. 1, n. 3, p. 59-81, 2009. Citado na página 23.

WAMBIER, L. R. Os contratos bancários e o código de defesa do consumidor. Revista de Direito do Consumidor, v. 18, n. 1, p. 125-132, 1996. Citado na página 25.

YEUNG, L. L. Bias, insecurity and the level of trust in the judiciary: the case of brazil. Journal of Institutional Economics, Cambridge University Press, v. 15, n. 1, p. 163-188, 2019. Citado na página 21. 